\title{
Characterisation of chemically related asbestos amphiboles of actinolite: proposal for a specific differentiation in the diagram (Si apfu versus $\mathrm{Mg} / \mathrm{Mg}+\mathrm{Fe}^{2+}$ )
}

\author{
Maxime Misseri ${ }^{1, *}$ and Didier Lahondere ${ }^{2}$ \\ ${ }^{1}$ Sorbonne University, UTC, EA 4297 UTC/ESCOM, CS 60313, 60205 Compiègne Cedex, France \\ 2 B.R.G.M., 3, Avenue C. Guillemin, BP 36009, 45060, Orléans Cedex 2, France
}

Received: 11 October 2018 / Accepted: 11 October 2018

\begin{abstract}
Aggregates and rocks from quarries located in metropolitan France and New Caledonia, all likely to contain asbestiform amphiboles, were analysed by a routine laboratory (AD-LAB). Morphological observations were made using transmission electron microscopy and chemical analyses were obtained with energy dispersive $\mathrm{X}$-ray spectroscopy. The chemical analyses obtained from amphiboles were treated in such a way that they could be plotted in a diagram ( $\mathrm{Si}$ apfu versus $\mathrm{Mg} / \mathrm{Mg}^{+} \mathrm{Fe}^{2+}$ ). The points corresponding to analysed particles, classified as asbestos, define a broader compositional domain than that corresponding to the compositional areas of actinolite and tremolite. The creation of two new domains is proposed. Samples of basic metavolcanics and amphibolites collected by the Geological and Mining Research Bureau (BRGM) in different quarries of the Armorican Massif and the Massif Central containing calcic amphibole fibres have been the subject of polarized light microscope and electron microprobe analyses. The representative points of the spot chemical analyses performed on the very fine and ultrafine fibres are contained in the range defined previously. The diagram that has been determined from chemical analyses coupled with morphological and dimensional observations can help the "routine laboratories" to better characterise asbestiform calcic amphiboles, but it also allows comparisons with geological observations.
\end{abstract}

Keywords: transmission electron microscopy and chemical analyses / chemical measurement / asbestos amphiboles of actinolite / morphological and dimensional observations

\section{Introduction}

Asbestos is a commercial term originally given to three asbestiform minerals corresponding to chrysotile, amosite (grunerite asbestos) and crocidolite (riebeckite asbestos), as well as three asbestiform mineral species found as contaminants of mineral fillers in materials used in buildings or industrial products (actinolite asbestos, tremolite asbestos and anthophyllite asbestos) [1,2]. Only these six minerals are currently affected by the regulations in force in France and in many countries.

Because of its physicochemical properties, asbestos has been widely used in construction and in industry, especially in the 1960s and 1970s and is today one of the main causes of occupational diseases in the world. Workers exposed to asbestos may develop pleural plaques, interstitial lung fibrosis, asbestosis, mesothelioma or lung cancer [3-5]. These diseases develop slowly with a latency of 20-30 years.

\footnotetext{
* Corresponding author: maxime.misseri@ad-lab.fr
}

Many countries banned the use of asbestos in the 1990s. A spike in deaths due to asbestos exposure is expected between 2015-2020 [6] in Europe. In France, a study [7] based on the National Mesothelioma Surveillance Program (Programme national de surveillance du mésothéliome PNSM) shows a stagnation in mortality in 2012 but not yet a decrease.

Interest in asbestos exposure in the natural environment is more recent. The link made by Peipins et al. [8] in 2003 between high mortality and many respiratory diseases associated with the inhalation of asbestos by the miners and the inhabitants of Libby in the state of Montana (United States), with the presence of asbestos-contaminated vermiculite, has attracted the attention of federal health authorities, leading the country to undertake an inventory of natural materials likely to contain asbestos in all states [9-11] in order to prevent exposures related to the use of these materials.

In France, asbestos has been particularly researched in asphalt concrete since 2010 because chrysotile fibres were voluntarily added as fillers in some asphalt concrete until 


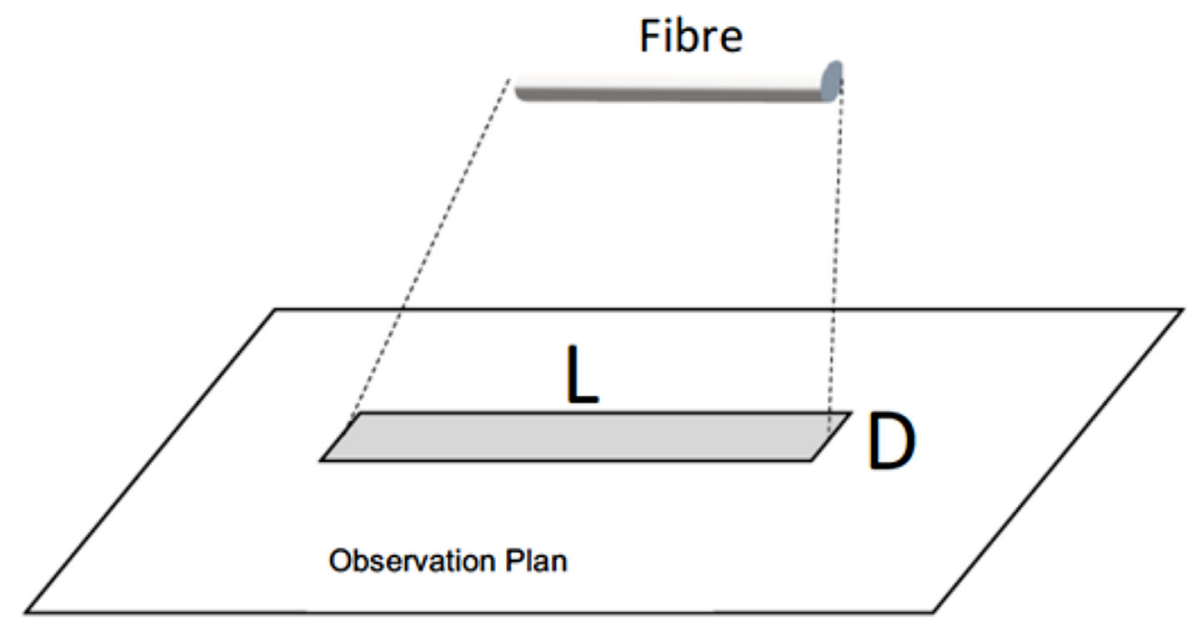

Fig. 1. L: length of a fibre, D: width of a fibre in an ideal case, $\mathrm{L}$ reported in the article is a minimum value because the fibre can be angled relative to the observation plane. The fibres may have a non-cylindrical section, D corresponds to the observed width of the fibres which is taken as reference and may be slightly different from the actual section of the fibre.

the early 1990s. As of 2013, several routine analyses conducted by laboratories specialising in asbestos detection (LSAD) have detected the presence of actinolite asbestos fibres in aggregates of natural origin. Widely used in the manufacture of asphalt and concretes or in the installation of ballasts, these aggregates are derived from natural materials (rocks) processed in quarries. The identification of actinolite asbestos fibres in asphalt concrete samples led the administration to conduct, as of the end of 2013, studies aimed at assessing the asbestos-containing potential of several types of rocks currently processed in quarries. As a continuation of this work, provisions have also been made to acquire precise geological information on the deposits most affected by the possible presence of asbestos in the materials used.

The objective of this work is to characterise, from a chemical point of view, asbestiform amphiboles that have a chemical composition close to actinolite. These minerals are found in rocks and more rarely in building materials. These amphiboles have been little described. Our role, as Meeker explained in 2009 [12], is not to determine whether these asbestiform amphibole varieties are pathogenic. This is the range of physicians, hygienists and biologists. The analytical approach of geologists and LSADs is different. However, their results converge when they are reported in the same diagram.

The samples analysed in the context of the present study were mostly collected in metropolitan France, in different geological contexts corresponding to the Armorican Massif (Brittany, Vendée), the Massif Central (Limousin) and the external crystalline massifs of the chain of the Alps. The other samples were taken in New Caledonia. All these samples were taken by geologists and then analysed, some at an LSAD (AD-LAB) and others at the BRGM laboratories. The analytical protocols monitored by AD-LAB and the BRGM are presented below.

The approach selected was to define a specific diagram obtained from the processing of the chemical spectra acquired during routine analysis by AD-LAB on fibres released after the grinding of quarry aggregates.
Morphological observations were made using a TEM, and spot chemical analyses were performed with an EDS analyser. All the particles tested were classified as asbestiform on the basis of criteria from the ISO 22262-1 standard, criteria from the bibliography or morphological criteria for asbestos fibres defined by the WHO. The minerals were classified according to the nomenclature of IMA 12 [13]. The proposed diagram is superimposed on the diagram ( $\mathrm{Si}$ apfu versus $\mathrm{Mg} / \mathrm{Mg}+\mathrm{Fe}^{2+}$ ) first proposed by Leake et al. (1997) [14] and includes a range corresponding to calcic amphiboles likely to have an asbestiform morphology. This range overlaps in particular with the ferro-actinolite range and with that of the most siliceous hornblendes.

Spot chemical analyses acquired according to the geological approach have been reported on the same diagram. These are the observations and measurements made by the BRGM with an electron microprobe (EMP) equipped with a wavelength dispersive spectroscopy (WDS).

\section{Procedures and analytical techniques}

\subsection{Definitions and terminology used}

The definition of a fibre used in this study is that proposed in standard NF X 43-050, namely, an elongated particle with parallel or stepped sides. A fibre is defined as having an equal $L / D$ ratio greater than or equal to 3 and a minimum length of $0.5 \mu \mathrm{m}$ (Fig. 1).

The adjectives prismatic, acicular and asbestiform refer to the morphological characteristics of amphiboles. The term prismatic describes a crystalline form characterised by a dominant elongated axis and two axes perpendicular to this elongation, which are shorter and of approximately equal length [15]. The term acicular applies to crystalline forms corresponding to very fine minerals whose transverse dimensions are very small compared to its length, that is to say, needle-shaped [16]. The term fibrous applied according to the "Committee on Non-Occupational Health Risks of Asbestiform Fibers from 1984" [17] to a single mineral is a 
mineral that resembles an organic fibre like hair or cotton (long, thin and has the appearance of a needle). If the fibres are separable, have tensile strength and are flexible, they are asbestiform fibres. If these minerals have the fragility conventionally encountered, they are acicular fibres. Two classes of non-asbestiform fibres have been observed in the geological component: we will call them very fine fibres and fine fibres.

Under the light microscope, the asbestiform habit is defined as [18] "a fibrous silicate mineral comprised of fine, flexible, readily separable fibers, having a high tensile strength and the following characteristics as individual fibers or bundles:

1. Mean aspect ratio ranging from 20:1 to 100:1 or higher for fibers longer than $5 \mu \mathrm{m}$;

2. Very thin fibrils, usually less than $0.5 \mu \mathrm{m}$ in width;

3. Parallel fibers occurring in bundles; and

4. One or more of the following:
a. Fiber bundles displaying splayed ends,
b. Matted masses of individual fibers,
c. Fibers showing curvatures."

\subsection{Sampling and analytical protocols}

Two analytical protocols were used (Fig. 2): that of $\mathrm{AD}-\mathrm{LAB}$, a laboratory specialising in asbestos detection (LSAD), and that of the BRGM organisation specialised in geological studies and mining research.

\subsubsection{AD-LAB}

LSADs usually receive more or less large samples, consisting of heterometric rock fragments. These are most often samples of the "geological" type (rock fragment the size of a fist), more or less coarse aggregate samples (from 0.5 to $2 \mathrm{~kg}$ depending on the particle size) or pieces of asphalt cores. LSADs only very rarely have information about the source and geological characteristics of the samples received. First, the sample is crushed and then observed under a polarized light microscope (PLM). The ground fractions are then processed in such a manner that they can be observed and analysed by scanning electron microscopy (SEM) or by TEM transmission (Fig. 3) equipped with a microanalysis system with an energy dispersive X-ray spectrometer (EDS). When a chemical analysis is performed on a fibre, the results obtained are compared with tables associated with standards (e.g. VDI 3492 [19], ISO 14966 [20]) or published by human health research organisations (INSERM [21]). The samples studied by AD-LAB correspond to fragments of natural rocks. For safety reasons and to avoid cross-contamination, these samples have been systematically considered as likely to contain asbestos. Upon receipt, the packages were opened under a HEPA exhaust hood and the samples repackaged with double bagging that was completely airtight. The samples received were previously observed using a binocular loupe. In the presence of a "geological" sample, the observation concerned all sides of the sample. In the case of a homogenised sample after grinding (aggregates), only a supposedly representative fraction was taken into

\section{Geological approach}

LSAD approach
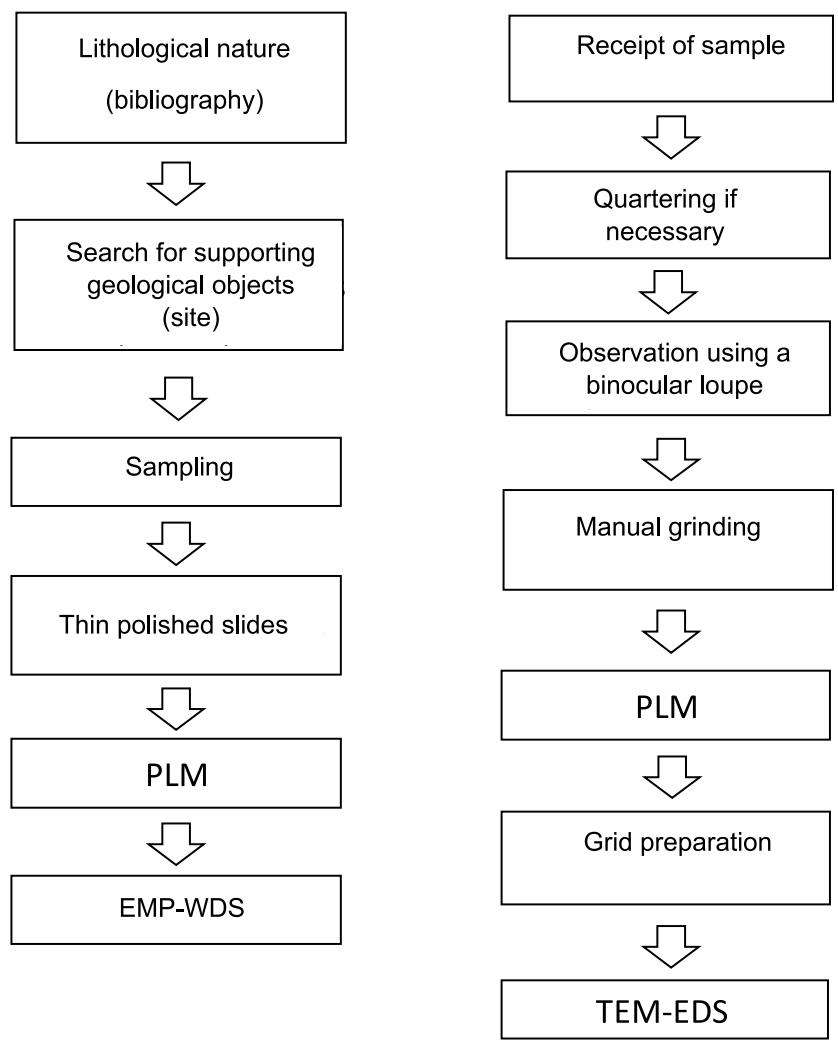

Fig. 2. Flowcharts describing the successive stages constituting the geological approach and the approach of the AD-LAB laboratory.

account. If fibres are observed in the preparation, they are directly sampled. The analyst also identifies all the microstructures that may contain fibres, so that they can be selected for the sampling of the subsample(s). Each subsample has a mass between 300 and $500 \mathrm{mg}$.

Each subsample is then ground using a mortar and pestle [22], crushed with a spatula or split using a scalpel, according to its initial consistency.

When fibres are observed in a prepared subsample, they are mounted between a slide and coverslip within known refractive indices (RI), to be observed in PLM. Since actinolite is the most common asbestiform mineral in the natural rocks of the regions involved in this study, the mounting is first carried out in a liquid with an RI of 1.640 (identification of actinolite) and, if necessary, in a liquid with a specific RI for another variety of asbestos. When the fibre is thick enough, it is identified using a McCrone lens. When no fibre is visible in the prepared subsample, a small amount of material is mounted between a slide and coverslip. In this study, the identifications made using the PLM were not used but the observations contributed to a better knowledge of the samples submitted for analysis.

Prepared subsamples are placed in a $50 \mathrm{ml}$ plastic vial. Deionized water is added. A concentration of particles in the preparation that is too large will cause material overload on the copper grids that are used for analytical 

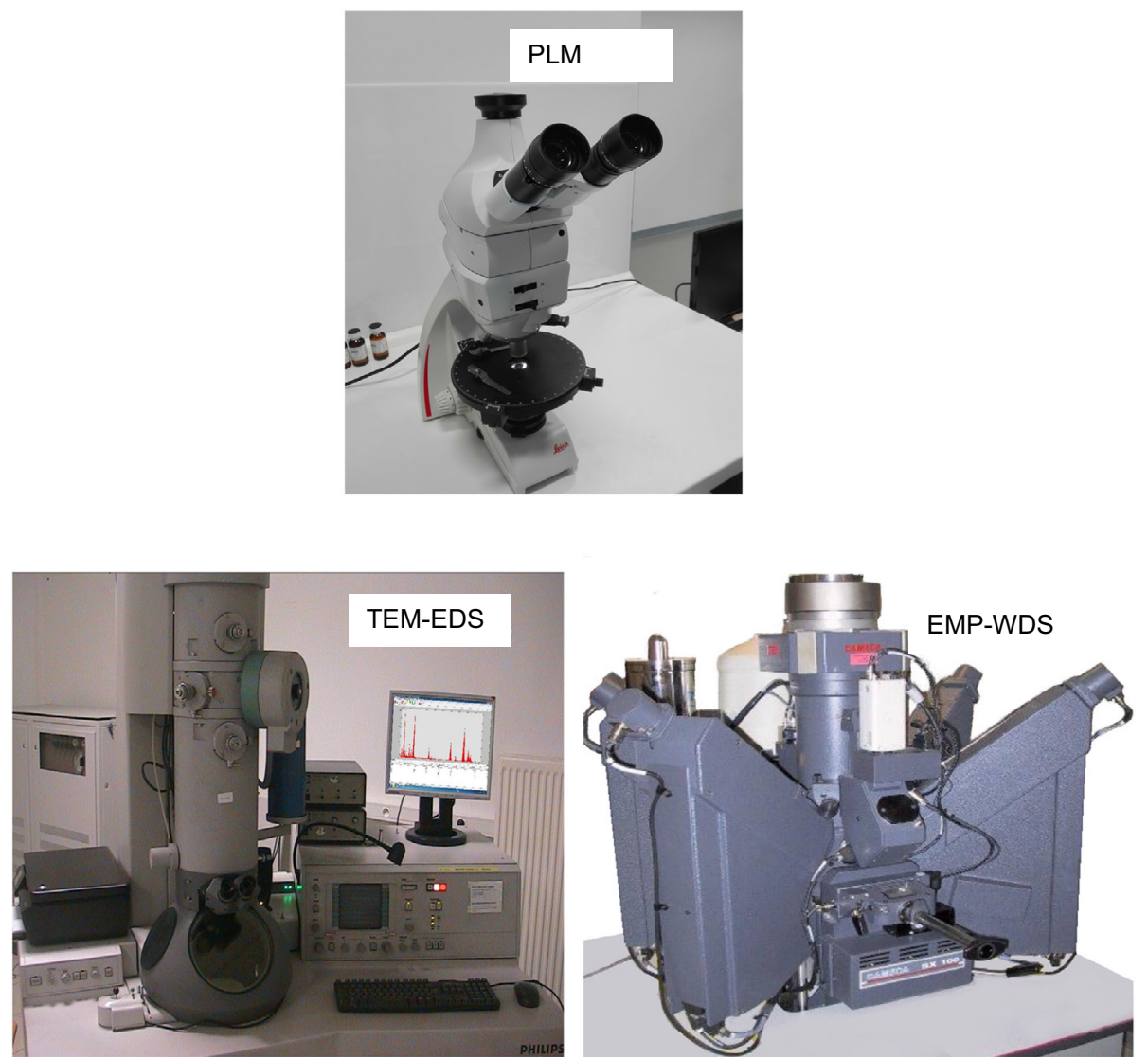

Fig. 3. Photos of a polarized light microscope (PLM), a CM200 transmission electron microscope equipped with an EDS microanalyser, a Cameca SX 100 electronic microprobe equipped with WDS microanalysers.

TEM observation and will prevent the detection of fibres. Dilution is adjusted according to the transparency, the objective being to obtain less than $20 \%$ of electron-dense material on the grids. The vial is submitted to ultrasound for $1 \mathrm{~min}$ to resuspend the deposits as much as possible. A grid on which a carbon film has previously been placed is held in a horizontal position by clamping tweezers, approximately $15 \mathrm{~cm}$ under a heat lamp. After shaking the vial, a drop is taken using a micropipette and placed on the carbon film on the analytical TEM grid (drop mount technique). The drop dries on the grid for about $15 \mathrm{~min}$ under the heat lamp.

The TEM-EDS analyses were performed using a FEI CM200 equipped with a SAMx NumeriX + EDS. The connection of the target and the measurement function of the microscope necessary for the measurement of the length and the width of the fibres was carried out using SPI microspheres and a network of Agar Scientific S106 crossline grating. The microanalysis system was verified using 1867 a reference materials with a maximum tolerated error of $10 \%$ per element. The diffraction measurement function was calibrated using the SPI gold standard.

Fibres, contained in six samples coming from amphibolite from the outer Alps, were analysed with both the TEM-EDS pair by AD-LAB and EMP by the University of Montpellier. The analytical protocol for the EMP analysis was the same as that used by the BRGM. The University of
Montpellier's EMP is an SX100 equipped with 5 WDS spectrometers. The operating conditions were $20 \mathrm{kV}$ accelerating voltage and $10 \mathrm{nA}$ beam current. Concentration calculations from the X-ray intensity of the microprobe were done from the work of Merlet (1994) [23]. Si, Al, $\mathrm{K}$, Ca and Mn counts were collected for $20 \mathrm{~s}$, Na counts for $10 \mathrm{~s}, \mathrm{Mg}$ counts for $30 \mathrm{~s}$ and Fe, Ti count [sic] for $40 \mathrm{~s}$, respectively.

In the present study, the structural formula of the analysed fibrous amphiboles was calculated from elemental analyses performed with an EDS or WDS microanalysis analysis system. The computation and determination of the mineral species was done with Andrew Locock's software (2013) [24] which follows the recommendations of the IMA 12. The values of Si (expressed in atoms per formula unit: apfu) and $\mathrm{Mg} / \mathrm{Mg}+\mathrm{Fe}^{2+}$ ratio were plotted on the diagram ( $\mathrm{Si}$ apfu versus $\mathrm{Mg} / \mathrm{Mg}+\mathrm{Fe}^{2+}$ ). An estimate of the ferric iron content $\left(\mathrm{Fe}^{3+}\right)$ was obtained by calculation with Andrew Locock's software.

With the EMP-WDS, the uncertainty on the $\mathrm{Mg} / \mathrm{Mg}+\mathrm{Fe}^{2+}$ ratio is negligible and that on the $\mathrm{Si}_{a p f u}$ value is on the order of $\pm 0.3 \%$. Using TEM-EDS, the uncertainty on these same values is greater. The major component of this uncertainty is the consideration of "maximum tolerated error" of $10 \%$ on the elementary analyses required in LSAD laboratories. The calculated uncertainty is $\pm 2.4 \%$ on $\mathrm{Si}_{a p f u}$ and on $\mathrm{Mg} / \mathrm{Mg}+\mathrm{Fe}^{2+}$. With 
Table 1. Origin of samples analysed by AD-LAB, 348 analyses of particles on 252 samples.

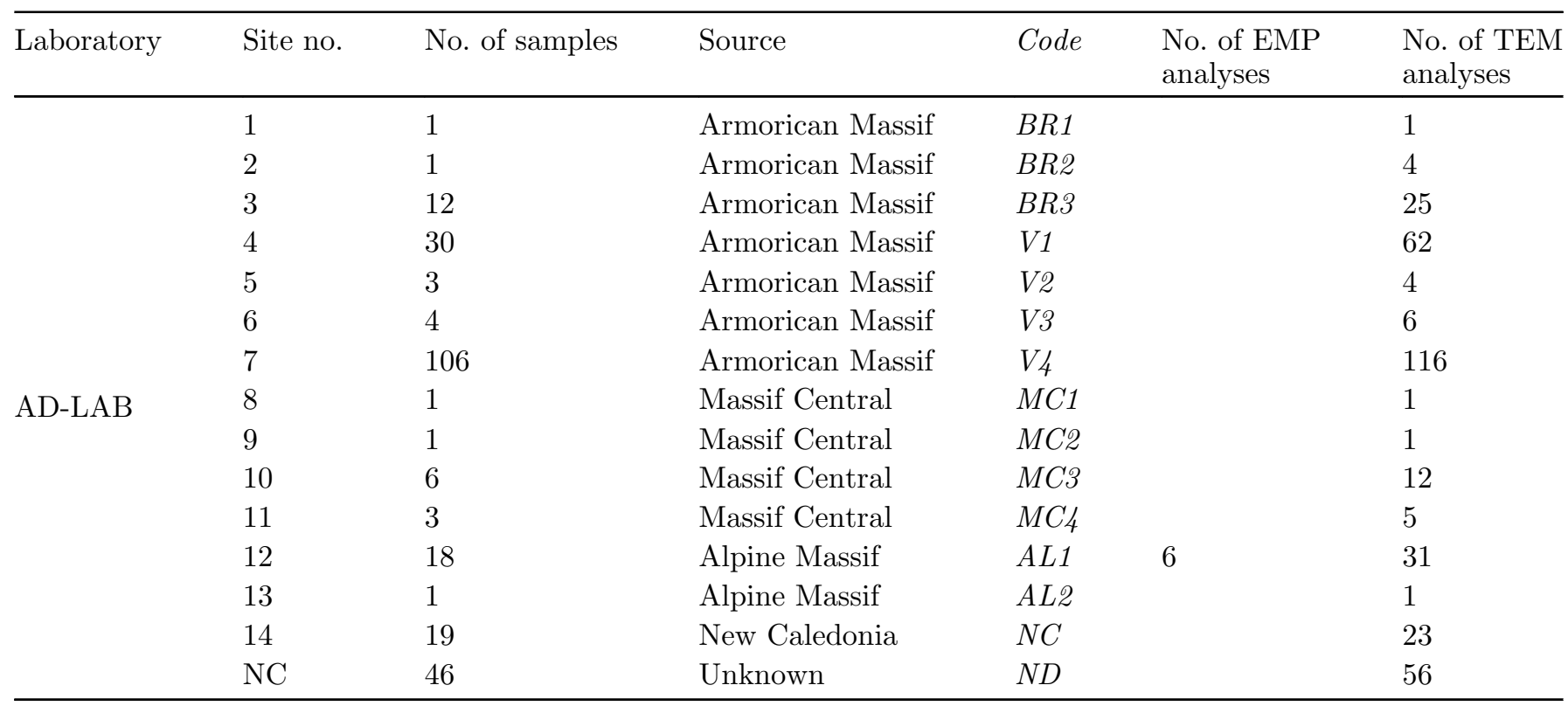

recent EDSs, the "maximum tolerated error" can be significantly reduced. As part of this study, it was decided to retain the value that is required and used by the majority of LSADs.

\subsubsection{BRGM}

Faced with a problem of identifying asbestos in a natural environment, a geologist first analyses the probability that potentially asbestos-containing fibrous occurrences may be present in this environment, based on existing data and taking into account several key parameters, in particular the lithological nature of the rocks considered, their mineralogical composition and their metamorphic and structural evolution [25]. At the end of this preliminary analysis, the geologist intervenes in the field to check the relevance of their diagnosis. The potentially asbestiform fibrous occurrences present in certain natural materials are more or less easy to identify, the main difficulties encountered depending in particular on the geological nature of the materials concerned, the type(s) of occurrence (s) present and the abundance of these occurrences. These potentially asbestiform fibrous occurrences are sometimes directly identifiable with the naked eye or with a field loupe but may be also undetectable to the naked eye and therefore only suspected at this stage of investigations. When potentially asbestiform fibrous occurrences are directly identified, it is possible for the geologist to establish a typology of these occurrences and to specify their distribution and abundance at the outcrop. Sampling is then mainly based on the collection of localized and targeted samples. Otherwise, sampling is based on taking representative samples of the rocks on the site.

In a consistent rock sample in which the presence of asbestiform fibres is suspected, the analytical protocol was based on the fabrication of thin sections intended to be studied by polarized light microscope (PLM) (Fig. 3) and, in the presence of fibres, with electron microprobe (EMP) (Fig. 3). PLM can be used to determine if amphiboles are present in the rock and, if so, to describe the morphology of these amphiboles and their relationship to other mineralogical constituents. EMP makes it possible to obtain spot chemical data from a mineral, the analysed zone corresponding to a volume of approximately $1 \mu \mathrm{m}^{3}$.

The solid samples were analysed with a CAMECA SXFive electron probe microanalyser (EPMA) equipped with five wavelength dispersive X-ray spectrometers (WDS) at BRGM (France) (Fig. 3). The operating conditions were accelerating voltage $\mathrm{HV}=15 \mathrm{kV}$ and beam current $\mathrm{BC}=10 \mathrm{nA}$. Samples were carbon coated under secondary vacuum (thickness: $\sim 20 \mathrm{~nm}$ ) using a CRESSINGTON 208 carbon coater. The system was calibrated with varieties of synthetic or natural minerals: orthoclase for $\mathrm{K}(\mathrm{K} \alpha)$, albite for $\mathrm{Na}(\mathrm{K} \alpha), \mathrm{Al}_{2} \mathrm{O}_{3}$ for $\mathrm{Al}(\mathrm{K} \alpha), \mathrm{MgO}$ for $\mathrm{Mg}(\mathrm{K} \alpha), \mathrm{Fe}_{2} \mathrm{O}_{3}$ for $\mathrm{Fe}(\mathrm{K} \alpha)$, andradite for $\mathrm{Si}(\mathrm{K} \alpha)$ and $\mathrm{Ca}(\mathrm{K} \alpha), \mathrm{MnTiO}_{3}$ for $\mathrm{Mn}(\mathrm{K} \alpha)$ and $\mathrm{Ti}(\mathrm{K} \alpha)$ and $\mathrm{Cr}_{2} \mathrm{O}_{3}$ for $\mathrm{Cr}(\mathrm{K} \alpha)$. Counting time was $10 \mathrm{~s}$ on peaks and $5 \mathrm{~s}$ on backgrounds. The phi-rho-Z method X-Phi [23] was used for intensity correction.

\section{Sampling and results}

\subsection{AD-LAB}

The analyses conducted by AD-LAB initially concerned 348 fibres from 252 samples (Tab. 1). These 348 fibres observed on the TEM and EDS analyses were acquired for each of them. The points representative of the compositions obtained were plotted on the diagram ( $\mathrm{Si}$ apfu versus $\left.\mathrm{Mg} / \mathrm{Mg}+\mathrm{Fe}^{2+}\right)$. Five sets of fibres were successively considered. The same fibre can belong to one or more sets.

In the first set, the retained fibres are characterised by dimensional criteria only $(L>5 \mu \mathrm{m}, D<3 \mu \mathrm{m}$ and $L / D$ ratio $>20$ ). According to ISO 22262-1, fibres that possess 


\section{Asbestiform Amphiboles (1/20 ratio)}

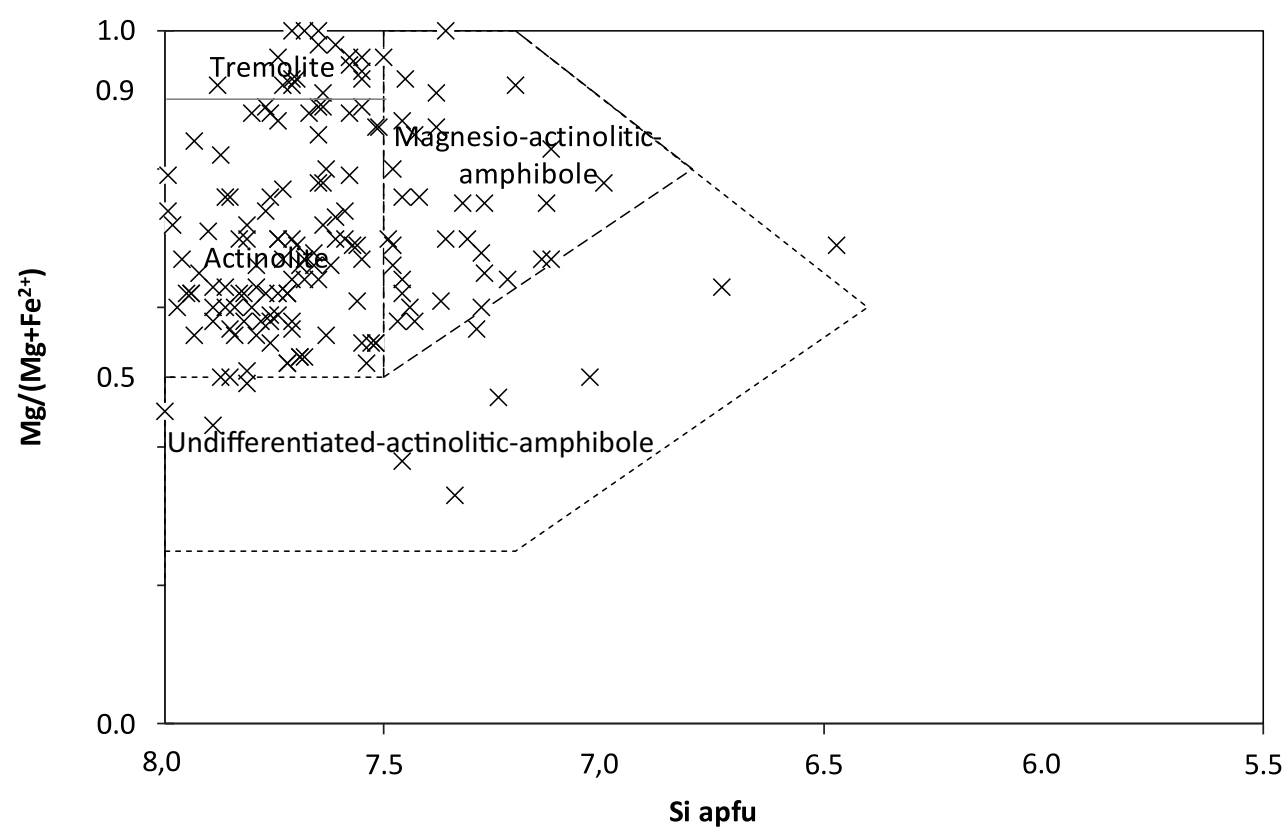

Fig. 4. First AD-LAB measurement set, amphiboles classified as asbestiform because they have elongation ratios greater than or equal to $1 / 20$.

these criteria are products of asbestiform fibrous structures. In the diagram ( $\mathrm{Si}$ apfu versus $\mathrm{Mg} / \mathrm{Mg}+\mathrm{Fe}^{2+}$ ), the representative points of the analysed amphibole fibres are predominantly in the compositional domains of actinolite and tremolite but several analyses correspond to less siliceous compositions $\left(\mathrm{Si}_{a p f u}<7.50\right)$ and for rare fibres to compositions richer in ferrous iron $\left(\mathrm{Mg} /\left(\mathrm{Mg}+\mathrm{Fe}^{2+}\right)<0.50\right)$ (Fig. 4).

In the second set, the retained fibres are characterised by two-dimensional criteria $(D<3 \mu \mathrm{m}, L / D$ ratio $>3)$ and the presence of diffraction contrast figures as described by Langer et al. (1974) [26]. These fibres are also considered by Langer as originating from asbestiform fibrous structures. These diffraction contrast figures are in the form of dark bands that cross the width of the particles. These bands may be rectilinear or curved, continuous or discontinuous (Fig. 5). The observation of these figures seems above all made possible by the fineness of the fibres observed. In the diagram $\left(\mathrm{Si}_{a p f u}\right.$ versus $\mathrm{Mg} /\left(\mathrm{Mg}+\mathrm{Fe}^{2+}\right)$, the representative points of the analysed amphibole fibres are predominantly located in the compositional domains of actinolite and tremolite but some analyses also extend to less siliceous compositions $\left(\mathrm{Si}_{\text {apfu }}<7.50\right)$ and for rare fibres to compositions that are richer in iron $\left(\mathrm{Mg} /\left(\mathrm{Mg}+\mathrm{Fe}^{2+}\right)<0.50\right)$ (Fig. 5). In the end, the compositional range obtained is close to that determined from the fibres retained in the first set (Fig. 4).

In the third set, the fibres taken into account have twodimensional criteria $(D<0.25 \mu \mathrm{m}$ and $L / D$ ratio $>3)$. These fibres are considered as coming from asbestiform minerals according to the data collected by Van Orden D.R. [27] In the diagram $\left(\mathrm{Si}_{a p f u}\right.$ versus $\mathrm{Mg} /\left(\mathrm{Mg}+\mathrm{Fe}^{2+}\right)$ (Fig. 6), the representative points of the fibres cover a compositional range close to that determined from the fibres retained in the first set (Fig. 4).
The fibres considered in the fourth set have the dimensional characteristics of inhalable fibres as defined by WHO $(L>5 \mu \mathrm{m}, D<3 \mu \mathrm{m}$ and $L / D$ ratio $>3)$. These dimensional characteristics have been defined by the WHO to specify the fibres to be taken into account in the analysis of air samples. These fibres are classified as asbestos according to current standard NF X 43050 in the French regulations relating to the determination by transmission electron microscopy of the concentration of asbestos fibres in ambient atmospheres. Part of the fibres considered in this fourth set probably originate from the fragmentation of three-dimensional, non-asbestiform actinolite crystals (cleavage fragments). The representative points of the fibres analysed nevertheless cover a compositional domain (Fig. 7) very similar to the three previous ones.

The fifth set concerns fibres whose characteristics are those of the fibres commonly taken into account during a search for asbestos in a material $(L>0.5 \mu \mathrm{m}, D<3 \mu \mathrm{m}$ and $L / D$ ratio $>3)$. Short fibres indicate the potential presence of a natural asbestos deposit. In Figure 8, the compositional range obtained is comparable to the fourth previous ones.

In the five sets considered, magnesio-ferri-hornblende is the most represented mineral outside the range of actinolite and tremolite, the percentage varying between 17.4 and 24.5 depending on the set considered (Tab. 2). This mineral covers the same area as magnesio-hornblende in the diagram $\left(\mathrm{Si}_{a p f u}\right.$ versus $\left.\mathrm{Mg} / \mathrm{Mg}+\mathrm{Fe}^{2+}\right)$. Ferro-hornblende, ferro-ferri-hornblende, ferri-tschermakite and ferro-actinolite are present in small quantities. Ferro-ferri-hornblende occupies the same domain as ferro-hornblende and ferritschermakite the same domain as tschermakite in the diagram $\left(\mathrm{Si}_{a p f u}\right.$ versus $\left.\mathrm{Mg} / \mathrm{Mg}+\mathrm{Fe}^{2+}\right)$. 

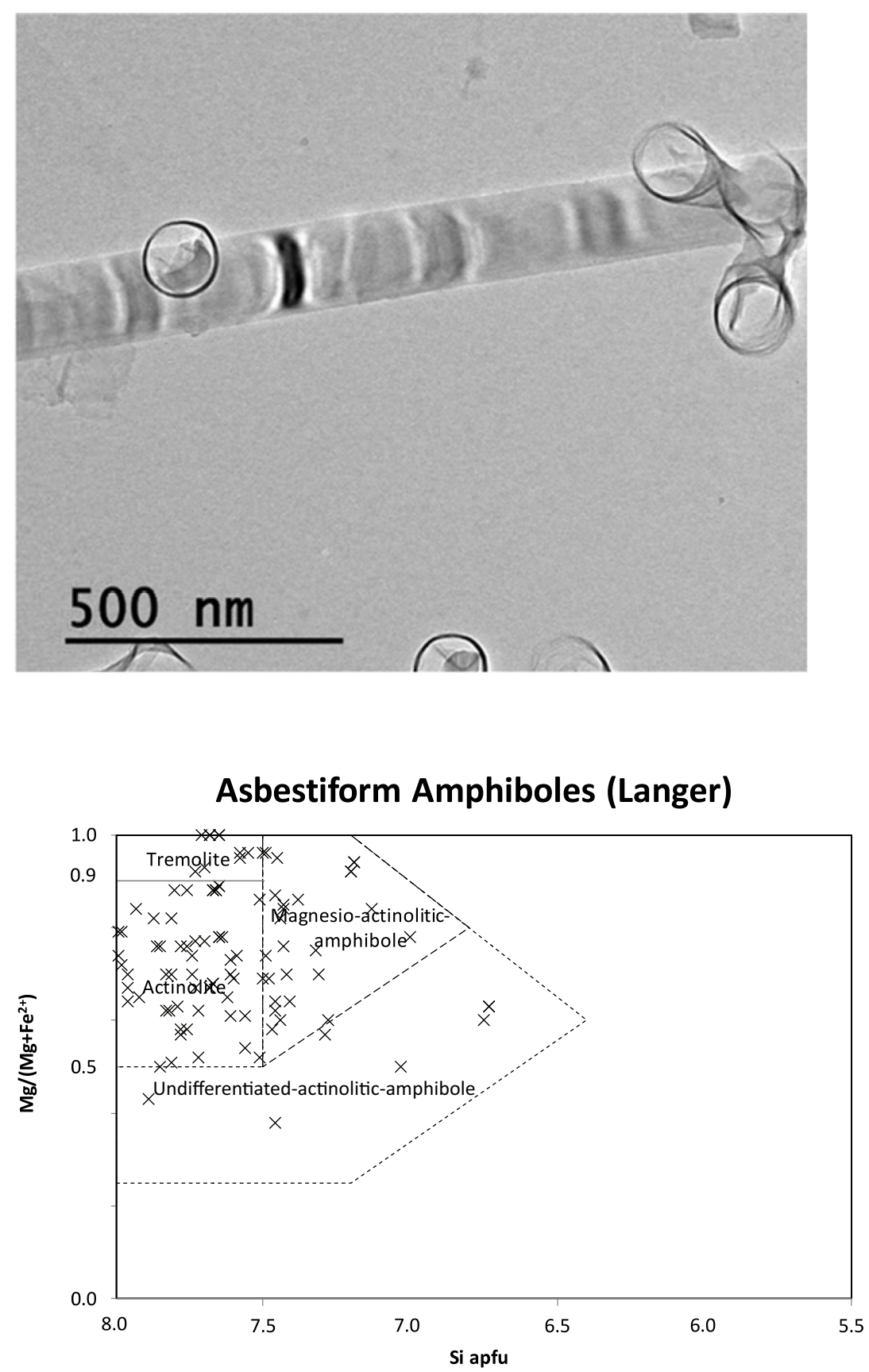

Fig. 5. Second AD-LAB test set, photo of an asbestos actinolite fibre showing Langer diffraction contrast figures, image obtained with Jeol 1200EX microscope from the SAPC of UTC Compiègne. A compositional range covered by amphiboles classified as asbestiform because they show Langer-type density contrasts on TEM from observations made in the laboratory.

In a second step, six samples from the French outer Alps were analysed by AD-LAB by coupling an electron microprobe approach and a TEM analysis. These samples correspond to amphibolites intersected by actinolite veins a few millimetres wide.

Spot chemical analyses were acquired with EMPWDS from actinolite-asbestos bundles observed on polished thin sections. The TEM-EDS chemical analyses were performed on actinolite-asbestos fibres observed on TEM, coming from ground elements from the same samples. The chemical analyses were acquired on the one hand with the University of Montpellier's EMP-WDS and on the other hand with AD-LAB's transmission electron microscope EDS. Calculations were then done using Locock's software. The results obtained are presented below for comparison (Tab. 3, Fig. 9). The values obtained are grouped in the same sector as the range of actinolite. The variability observed between the values is compatible with the variations observed on this type of material. The measurements with the 


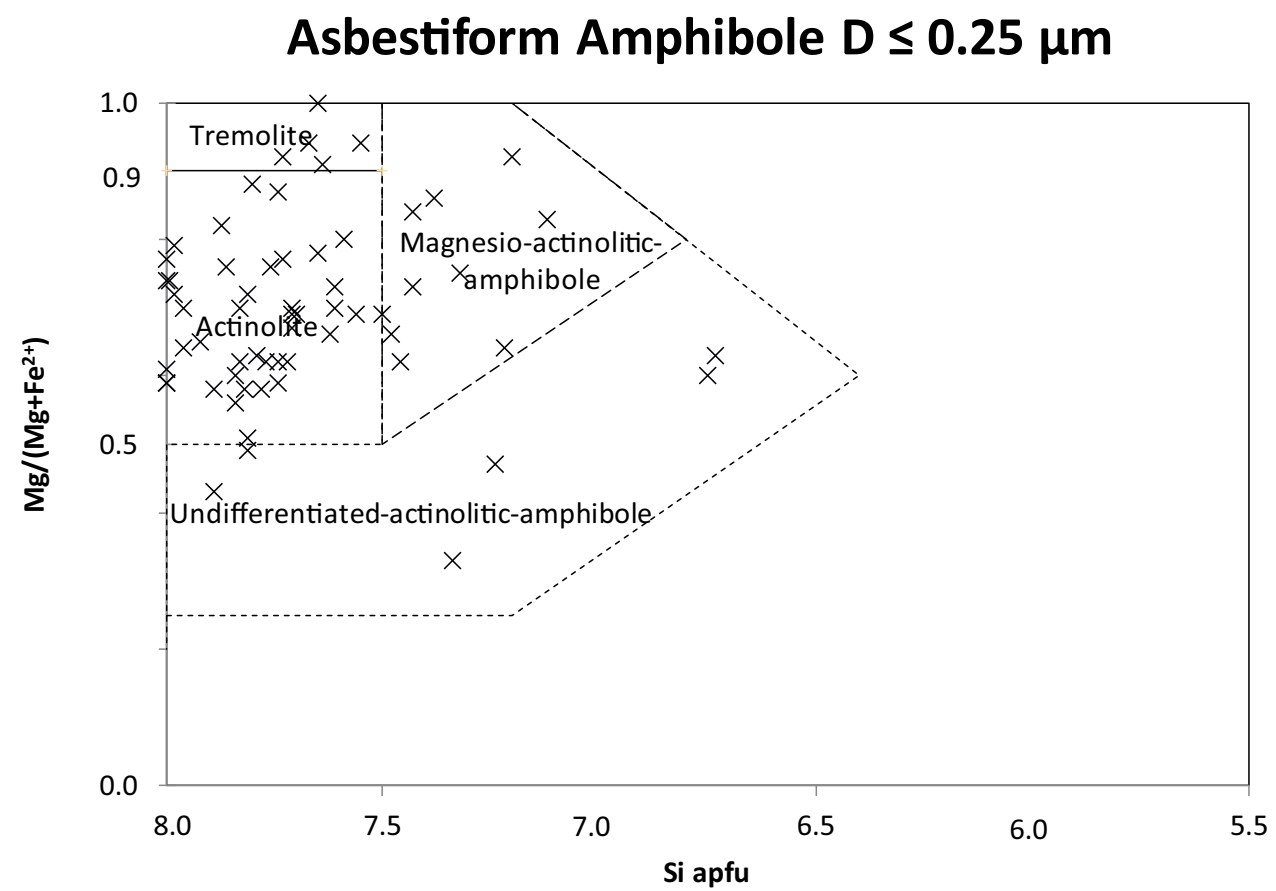

Fig. 6. Third set of AD-LAB measurements, compositional range covered by representative points for fibres with a diameter of less than $0.25 \mu \mathrm{m}$ and an elongation ratio greater than 3 .

\section{Amphibole fibres with the WHO dimension}

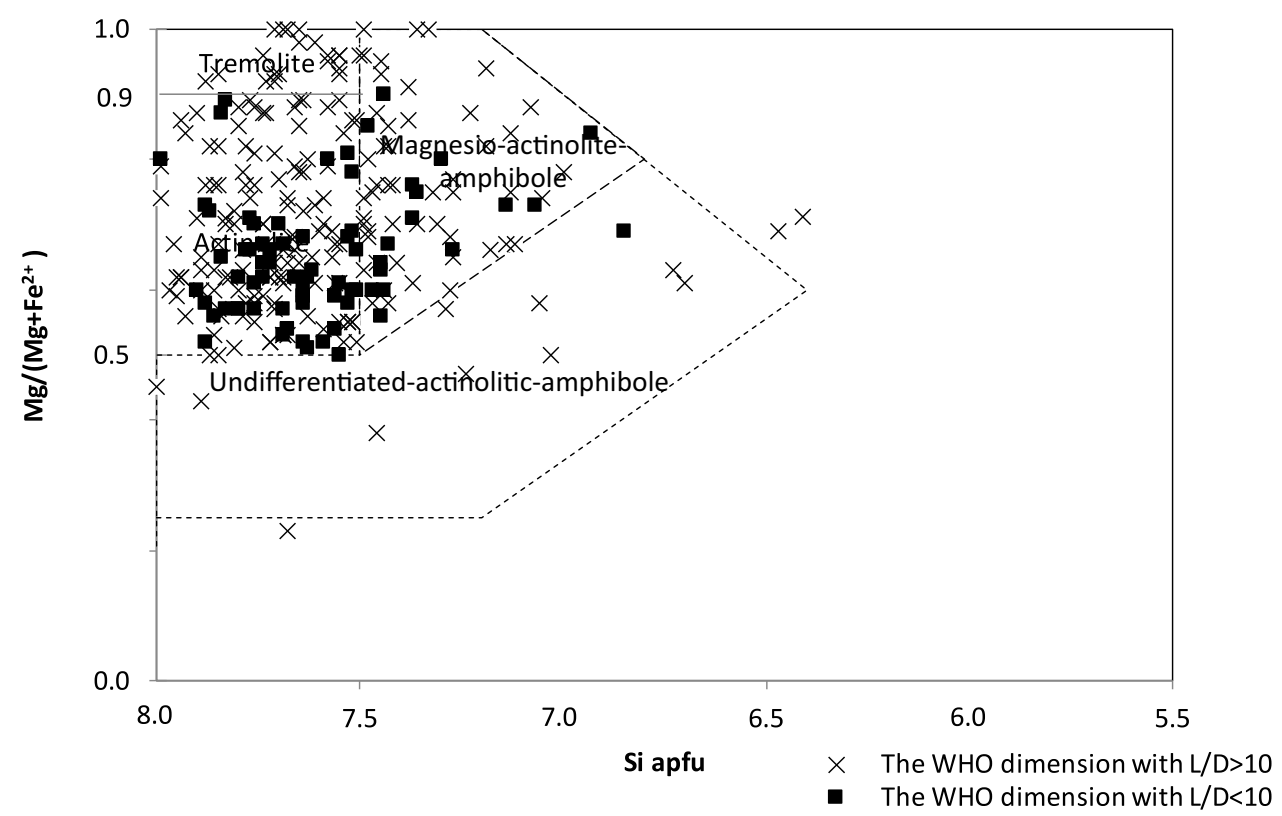

Fig. 7. Fourth set of AD-LAB measurements, composition range covered by fibres parallel to WHO dimensions $(\mathrm{L}>5 \mu \mathrm{m}, \mathrm{D}<3 \mu \mathrm{m}$ and $\mathrm{L} / \mathrm{D}$ ratio $>3$ ). The black squares represent the fibres with an $\mathrm{L} / \mathrm{D}$ ratio between 3 and 10 . Some of these fibres may correspond to cleavage fragments.

microprobe have been made at the base of the fibres in order to avoid the release of gases that occur when measurements are made with the evaporation of water trapped between the actinolite fibres. The measurements made with EDS were made from fibres released during grinding, which theoretically favours the fibres found in the heart of the veins. A variation in the chemical composition between the base and the end of the fibres can partly explain the variations observed between the two methods. 


\section{Fibres $\mathrm{L}>0.5 \mu \mathrm{m} \mathrm{D}<3 \mu \mathrm{m} \mathrm{L} / \mathrm{D}$ ratio $>3$}

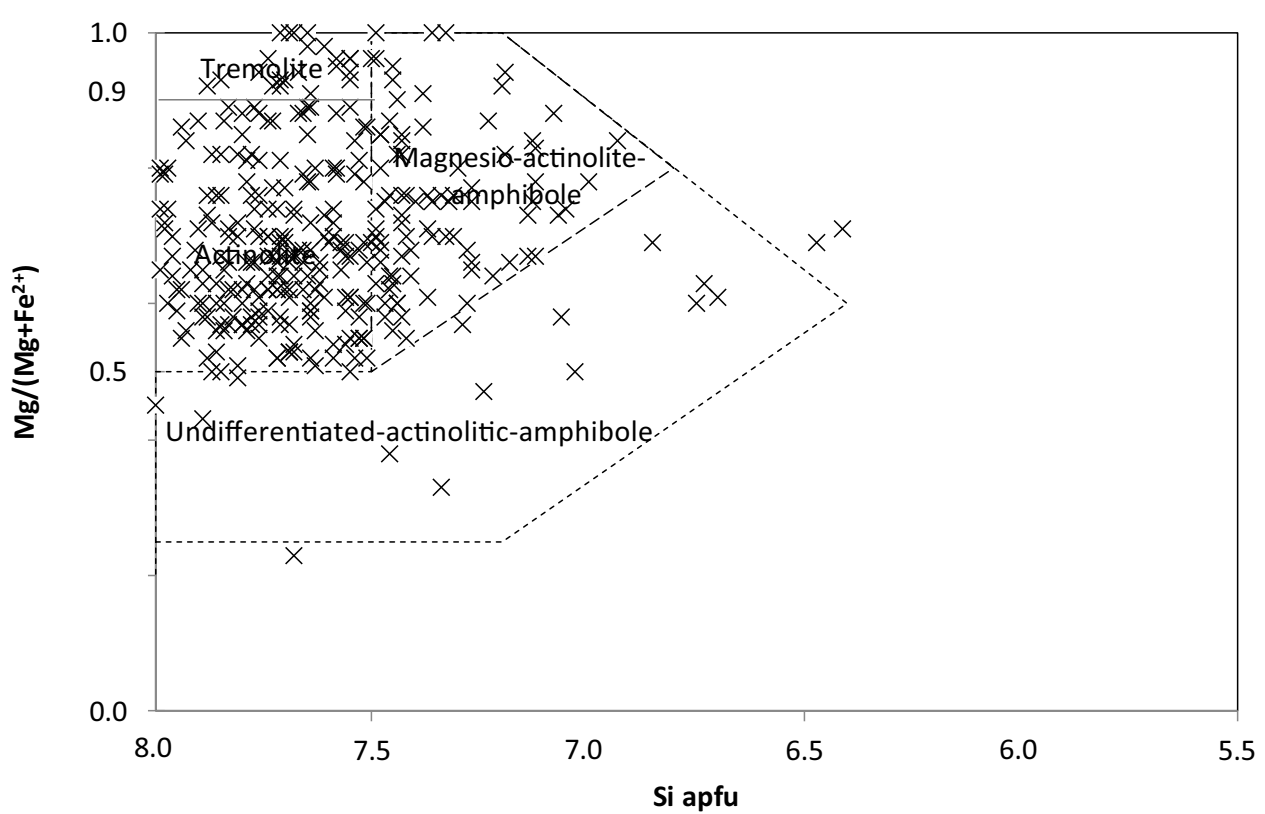

Fig. 8. Fifth set of AD-LAB measurements, composition field covered by fibres with edges parallel to the dimensions $(\mathrm{L}>0.5 \mu \mathrm{m}$, $\mathrm{D}<3 \mu \mathrm{m}$ and $\mathrm{L} / \mathrm{D}$ ratio $>3)$.

Table 2. Distribution of the mineralogical varieties according to the different sets considered on the AD-LAB test.

\begin{tabular}{|c|c|c|c|c|c|c|c|c|c|c|}
\hline Mineralogical variety & $L / D>20$ & & Langer & & $D \leq 0.25 \mu \mathrm{m}$ & & WHO & & $L>0.5 \mu \mathrm{m}$ & \\
\hline Tremolite & 13 & $7.6 \%$ & 7 & $7.4 \%$ & 5 & $8 \%$ & 19 & $6.6 \%$ & 22 & $6.3 \%$ \\
\hline Magnesio-hornblende & 2 & $1.2 \%$ & 3 & $3.2 \%$ & 2 & $3 \%$ & 4 & $1.4 \%$ & 7 & $2.0 \%$ \\
\hline Magnesio-ferri-hornblende & 30 & $17.4 \%$ & 23 & $24.5 \%$ & 9 & $15 \%$ & 59 & $20.5 \%$ & 71 & $20.3 \%$ \\
\hline Ferro-ferri-hornblende & 3 & $1.7 \%$ & 1 & $1.1 \%$ & 2 & $3 \%$ & 2 & $0.7 \%$ & 3 & $0.9 \%$ \\
\hline Ferro-actinolite & 3 & $1.7 \%$ & 1 & $1.1 \%$ & 2 & $3 \%$ & 3 & $1.0 \%$ & 4 & $1.1 \%$ \\
\hline Actinolite & 120 & $69.8 \%$ & 59 & $62.8 \%$ & 42 & $68 \%$ & 199 & $69.1 \%$ & 240 & $68.8 \%$ \\
\hline Ferri-tschermakite & 1 & $0.6 \%$ & 0 & $0.0 \%$ & 0 & $0 \%$ & 2 & $0.7 \%$ & 2 & $0.6 \%$ \\
\hline Total No. of particles & 172 & & 94 & & 62 & & 288 & & 349 & \\
\hline
\end{tabular}

\subsection{BRGM}

Sixteen samples analysed at the BRGM laboratories were taken from 16 different deposits (Tab. 4) in the Armorican Massif and Massif Central, all of them consisting of metamorphic basic rocks (low-grade meta-basalts, amphibolites) and gabbro-diorites. All samples analysed correspond to consistent samples from which several thin sections were made. The study of these thin sections using a polarized light microscope made it possible to describe the morphology of the amphiboles present and to measure the main dimensional characteristics of the fibrous amphiboles ( $L, D$ and $L / D$ ratio). The thin sections were all cut in a plane subparallel to the preferred elongation of the amphibole crystals. The existence of a weak obliquity between the elongation of these crystals and the surface observed under polarized light microscope leads one to consider the measured lengths $(L)$ as minimal and therefore to underestimate the elongation $(L / D)$ ratio.

Three classes of fibres were considered, classified in this work as fine $(D>10 \mu \mathrm{m})$, very fine $(2<D \leq 10 \mu \mathrm{m})$ and ultrafine $(D \leq 2 \mu \mathrm{m})$. In practice, the actual thickness of the ultrafine fibres is not measurable by optical microscopy. These ultrafine particles are those which have the morphological characteristics closest to those of the asbestiform fibres, in particular a very high elongation $(L / D$ ratio $>20)$ and curved in nature. Analyses (267) carried out on the electron microprobe then made it possible to acquire precise spot data concerning the chemistry of the identified fibrous amphiboles. This chemical information has very rarely been acquired from ultrafine amphibole fibres $(D \leq 2 \mu \mathrm{m})$ precisely because of their excessive fineness and their isolation in quartz, feldspar or carbonate matrices. The representative points 
Table 3. Chemical analysis of asbestos actinolite analysed in six samples of amphibolite with EMP-WDS and TEM-EDS from the same deposit of the outer Alps.

\begin{tabular}{|c|c|c|c|c|c|c|c|c|c|c|c|c|}
\hline & \multicolumn{6}{|c|}{ EMP-WDS results w\% } & \multicolumn{6}{|c|}{ TEM-EDS results w\% } \\
\hline & $\mathrm{A}$ & $\mathrm{B}$ & $\mathrm{C}$ & $\mathrm{D}$ & $\mathrm{E}$ & $\mathrm{F}$ & A & B & $\mathrm{C}$ & $\mathrm{D}$ & $\mathrm{E}$ & $\mathrm{F}$ \\
\hline $\mathrm{Na}_{2} \mathrm{O}$ & 0.21 & 0.50 & 0.08 & 0.17 & 0.11 & 0.15 & 1.67 & 1.34 & 0.54 & 0.69 & 0.73 & 0.10 \\
\hline $\mathrm{MgO}$ & 15.61 & 14.79 & 17.96 & 17.55 & 18.80 & 17.66 & 15.86 & 19.49 & 16.23 & 15.26 & 20.98 & 16.20 \\
\hline $\mathrm{Al}_{2} \mathrm{O}_{3}$ & 1.30 & 3.47 & 0.81 & 1.11 & 0.77 & 1.06 & 1.57 & 1.23 & 0.79 & 3.16 & 1.75 & 1.48 \\
\hline $\mathrm{SiO}_{2}$ & 54.69 & 50.65 & 56.13 & 56.35 & 56.93 & 55.19 & 57.31 & 55.47 & 57.47 & 58.04 & 57.35 & 57.28 \\
\hline $\mathrm{K}_{2} \mathrm{O}$ & 0.04 & 0.07 & 0.03 & 0.03 & 0.02 & 0.03 & 0.00 & 0.00 & 0.00 & 0.00 & 0.00 & 0.00 \\
\hline $\mathrm{CaO}$ & 12.79 & 12.06 & 12.95 & 13.09 & 13.30 & 12.95 & 11.31 & 12.72 & 15.10 & 12.86 & 13.40 & 17.46 \\
\hline $\mathrm{TiO}_{2}$ & 0.01 & 0.11 & 0.04 & 0.05 & 0.03 & 0.04 & 0.00 & 0.00 & 0.00 & 0.00 & 0.00 & 0.00 \\
\hline $\mathrm{MnO}$ & 0.36 & 0.24 & 0.26 & 0.32 & 0.24 & 0.28 & 0.00 & 0.00 & 0.00 & 0.00 & 0.00 & 0.00 \\
\hline $\mathrm{FeO}$ & 12.77 & 11.84 & 9.01 & 9.81 & 7.64 & 8.94 & 11.65 & 9.76 & 9.87 & 9.99 & 5.80 & 7.47 \\
\hline Total & 97.78 & 93.73 & 97.28 & 98.48 & 97.86 & 96.31 & 99.36 & 100.01 & 100.00 & 100.00 & 100.01 & 99.99 \\
\hline \multicolumn{7}{|c|}{ EMP-WDS results (apfu) } & \multicolumn{6}{|c|}{ TEM-EDS results (apfu) } \\
\hline$\overline{\mathrm{Si}}$ & 7.86 & 7.59 & 7.96 & 7.93 & 7.97 & 7.92 & 7.98 & 7.69 & 7.99 & 7.98 & 7.81 & 7.92 \\
\hline $\mathrm{Mg} / \mathrm{Mg}+\mathrm{Fe}^{2+}$ & 0.69 & 0.7 & 0.78 & 0.76 & 0.81 & 0.78 & 0.71 & 0.81 & 0.75 & 0.73 & 0.87 & 0.79 \\
\hline
\end{tabular}

EMP-WDS versus TEM-EDS Alps samples

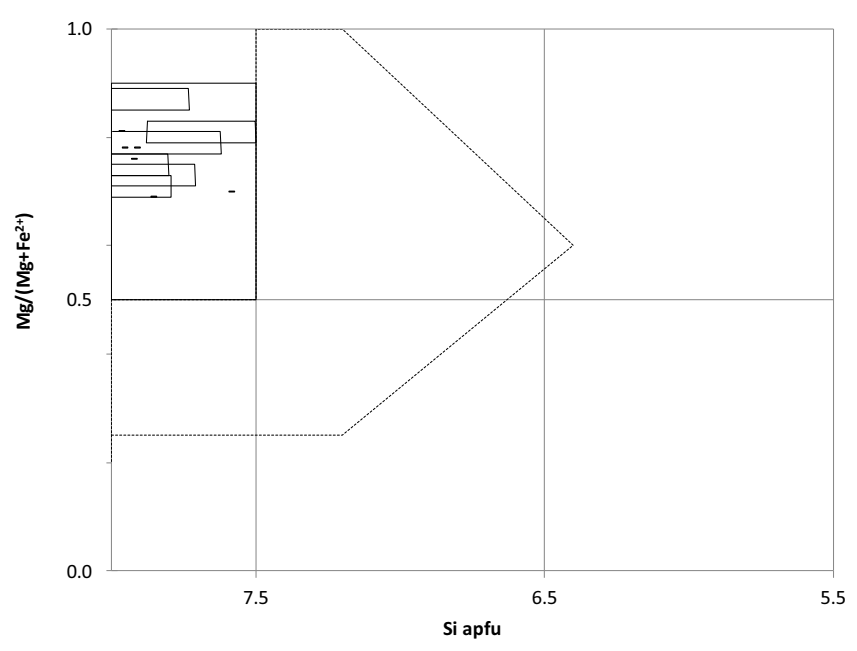

Fig. 9. Comparison of chemical analyses of actinolite asbestos carried out with EDS versus WDS reported on a diagram ( $\mathrm{Si}_{\text {apfu }} \mathrm{vs}$ $\left.\mathrm{Mg} / \mathrm{Mg}+\mathrm{Fe}^{2+}\right)$. The calculated uncertainty of the WDS measurements on the $\mathrm{Mg} / \mathrm{Mg}+\mathrm{Fe}^{2+}$ ratio is negligible, on $\mathrm{S}_{\text {iapfu }}$ it is plus or minus $0.3 \%$, with the EDS it is $2.4 \%$ on both values. The WDS measurements are represented by a line, the EDS measurements by a rectangle whose sides are proportional to the uncertainty.

of the analyses were plotted on the diagram ( $\mathrm{Si}_{a p f u}$ versus $\left.\mathrm{Mg} / \mathrm{Mg}+\mathrm{Fe}^{2+}\right)$, by classifying the fibres according to their diameter (Fig. 10).

The representative points for the fine fibres $(D>10 \mu \mathrm{m})$ are distributed over a large surface of the diagram $\left(\mathrm{Si}_{\text {apfu }}\right.$ versus $\mathrm{Mg} /\left(\mathrm{Mg}+\mathrm{Fe}^{2+}\right)$, from compositions very poor in silica and more or less magnesian corre- sponding to tschermakites and ferro-tschermakites $\left(\mathrm{Si}_{a p f u}<6.5 ; \mathrm{XMg}>0.2\right)$ to very siliceous and magnesian poles corresponding to actinolites and tremolites $\left(\mathrm{Si}_{a p f u}>\right.$ 7.5; XMg > 0.5). Moderately siliceous compositions are also very well represented, in particular magnesiohornblendes. In this same figure, the representative points for the very fine fibrous amphiboles $(2<D \leq 10 \mu \mathrm{m})$ define a substantially larger compositional field than that attributed to actinolite and tremolite. The electron microprobe compositions show that these very fine fibrous amphiboles correspond partly to actinolites and to tremolites and for the rest to relatively siliceous ferroactinolites and hornblendes (Fig. 10). The representative points for ultrafine fibrous amphiboles, asbestiform or potentially asbestiform define an even smaller field that does not extend much beyond the hornblende range (Fig. 10).

The representative points for the very fine and ultrafine fibres are all, with the exception of two points, inside the compositional ranges covered by the asbestiform calcic fibres analysed by AD-LAB. The AD-LAB data show a densification of these points in the most siliceous sector of magnesio-ferri-hornblende and magnesio-hornblendes. Measurements made using TEM-EDS (Fig. 11) on the analysable fibres with the EMP have comparable results.

\section{Discussion}

The reference for actinolite-asbestos in the CAS registry is RN 77536-66-4 REGISTRY* with the mention C.T.S. (Concept Type Substances). The fact that it is registered with a number followed by an asterisk and the mention CTS indicates that actinoliteasbestos has not been registered as a specific substance 
Table 4. Origin of samples analysed by BRGM, 267 analyses of particles on 16 samples.

\begin{tabular}{lllllll}
\hline & Site no. & $\begin{array}{l}\text { No. of } \\
\text { samples }\end{array}$ & Geological domain & Site & Lithology & EMP analyses \\
\hline 1 & 1 & Armorican Massif & AM1 & Amphibolite & 27 \\
2 & 1 & Massif Central & CM1 & Amphibolite & 4 \\
& & 1 & Armorican Massif & AM2 & Amphibolite & 6 \\
BRGM & 1 & Massif Central & CM2 & Amphibolite & 6 \\
& 5 & 1 & Armorican Massif & AM3 & Amphibolite & 15 \\
& 5 & 1 & Armorican Massif & AM4 & Gabbro-diorite & 40 \\
& 1 & 1 & Armorican Massif & AM5 & Gabbro-diorite & 46 \\
& 1 & 1 & Armorican Massif & AM6 & Meta-basalt & 10 \\
& 1 & 1 & Massif Central & CM3 & Amphibolite & 16 \\
& 11 & 1 & Armorican Massif & AM7 & Meta-basalt & 6 \\
& 12 & 1 & Armorican Massif & AM8 & Amphibolite & 5 \\
& 13 & 1 & Armorican Massif & AM9 & Meta-basalt & 14 \\
& 15 & Massif Central & CM4 & Gabbro-diorite & 11 \\
& 1 & Armorican Massif & AM10 & Amphibolite & 37 \\
\end{tabular}

that has been precisely characterised. The Environmental Protection Agency's (EPA) Substance Registry Services (SRS), which is responsible for collecting information on substances controlled by the EPA, has a chemical definition of actinolite, which is that of geologists $\left(\mathrm{Ca}_{2}\left(\left(\mathrm{Mg}_{0.5-0.89} \mathrm{Fe}_{0.11-0.5}\right)_{4.5-5} \mathrm{Al}_{0-0.5}\right)\right.$ $\left.\left(\mathrm{Si}_{7.5-8} \mathrm{Al}_{0-0.5}\right)(\mathrm{OH})_{2} \mathrm{O}_{22}\right)$. In France, laboratories that carry out routine asbestos research use for the most part, as a chemical reference, that of the Kirk-Othmer [28] table, which was included in the INSERM report. In the Kirk-Othmer table, the chemical composition of the minerals is expressed in oxide weight percent ranges for the chemical elements $\left(\mathrm{SiO}_{2}, \mathrm{MgO}, \mathrm{FeO}, \mathrm{Fe}_{2} \mathrm{O}_{3}, \mathrm{Al}_{2} \mathrm{O}_{3}\right.$, $\left.\mathrm{CaO}, \mathrm{K}_{2} \mathrm{O}, \mathrm{Na}_{2} \mathrm{O}, \mathrm{H}_{2} \mathrm{O}\right)$. Ferric iron $\left(\mathrm{Fe}_{2} \mathrm{O}_{3}\right)$ and water $\left(\mathrm{H}_{2} \mathrm{O}\right)$ are not measured by laboratories. When the values given for actinolite-asbestos are varied, the structural formula of the theoretical minerals thus obtained is calculated and reported on the diagram $\left(\mathrm{Si}_{a p f u}\right.$ versus $\left.\mathrm{Mg} / \mathrm{Mg}+\mathrm{Fe}^{2+}\right)$, the representative points occupy a field less extensive than that proposed by geologists (Fig. 12) and partially overlap with the field of siliceous magnesio-hornblende and magnesio-ferrihornblende. In Figure 12, only the values of $\mathrm{Si}, \mathrm{Mg}$, $\mathrm{Fe}^{2+}$ and $\mathrm{Al}$ for which the sites $\mathrm{A}, \mathrm{B}, \mathrm{C}, \mathrm{T}$ and $\mathrm{W}$ are balanced in the theoretical mineral have been considered. In Europe, the German standard VDI 3492, often used, also gives the composition of actinolite-asbestos in oxide weight percent (the same elements as in the table of Kirk-Othmer). The compositions for actinoliteasbestos cover a field similar to that of the Kirk-Othmer table but with a slightly larger area (Fig. 12).

Taking into account the most used composition domains on the one hand, and the results of the measurements made in the framework of this study on the other hand, led to a re-examination of the limits of the actinolite-asbestos range, which should be extended in such a way as to cover a part of the magnesiohornblende fields and the magnesio-ferri-hornblendes (the most siliceous ones), ferro-hornblendes and ferroferri-hornblendes and ferro-actinolites as represented on the diagram ( $\mathrm{Si}_{a p f u}$ versus $\mathrm{Mg} / \mathrm{Mg}+\mathrm{Fe}^{2+}$ ) (Fig. 13). As part of the search for asbestos from natural materials, this differentiation appears more suitable than compositional ranges.

The external contour of the compositional field of calcic amphiboles other than tremolite and actinolite and likely to be encountered under an asbestiform morphology was defined from fibres classified as asbestiform in the first three AD-LAB sets.

The first domain is composed essentially of magnesioferri-hornblende and this regardless of the set of fibres considered. The density of localized analyses in this area, excluding actinolite and tremolite, is significant and varies between 76 and $84 \%$ of the particles analysed according to the set considered. This domain has been termed "magnesio-actinolitic-amphibole" with reference to the domains actinolitic hornblende and tremolitic hornblende that had been defined in the IMA 1978 [29] and were abandoned in IMA 97 [14]. The magnesio-actinoliticamphibole domain largely encompasses the actinolitic hornblende and tremolitic hornblende domains of IMA 78. It also encompasses a large portion of the less siliceous fields of magnesio-hornblende and magnesio-ferri-hornblende, covered by the analysis ranges provided by Kirk and Othmer and VDI 3492.

The second domain is composed of magnesio-hornblende, magnesio-ferri-hornblende, ferro-ferri-hornblende and ferro-actinolite. The analyses are few and scattered. This area has been called "undifferentiated-actinoliticamphibole." 

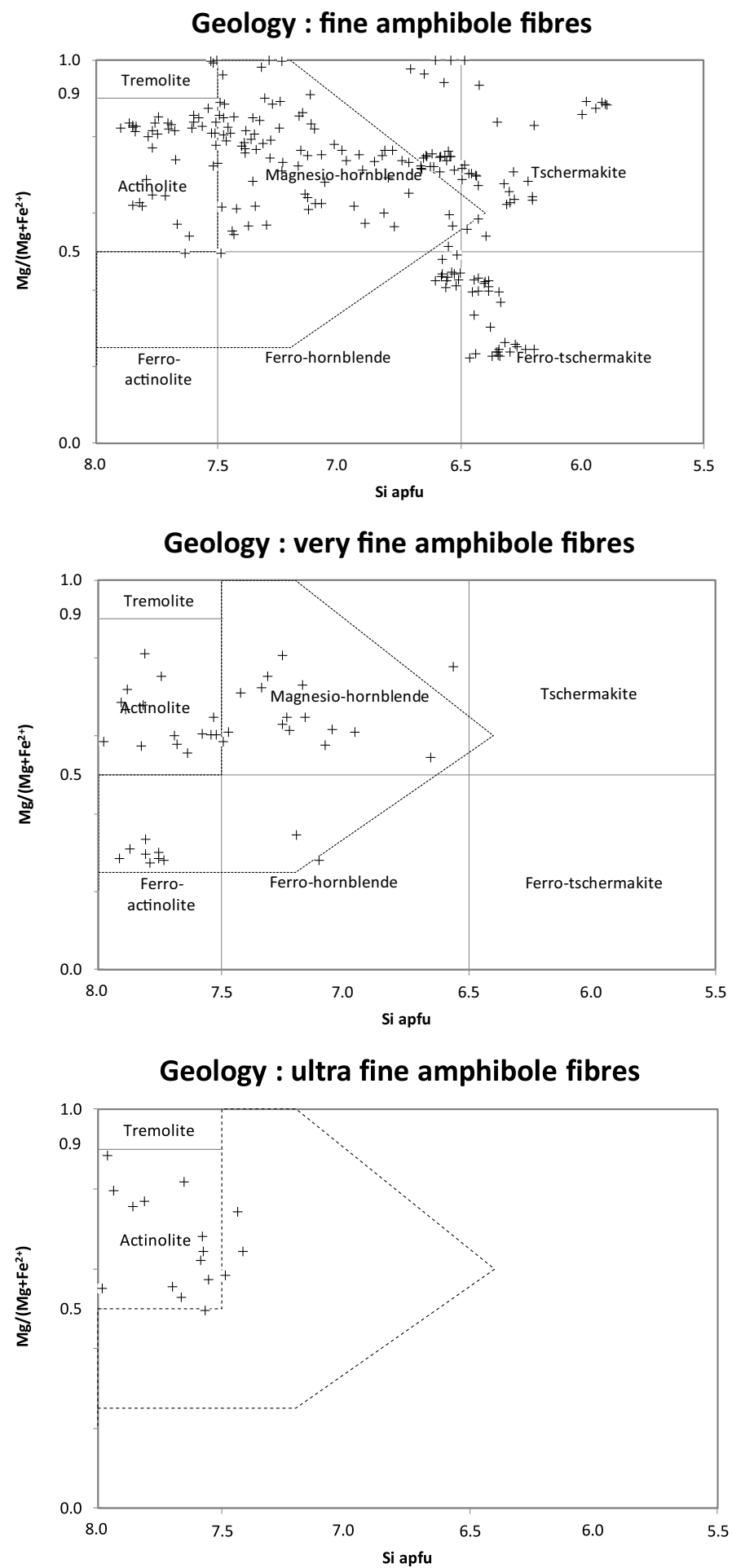

Fig. 10. BRGM, Composition, fine, very fine and asbestiform amphibole fibres observed, shown in the diagram $\left(\mathrm{S}_{\text {iapfu }} \mathrm{vs} \mathrm{Mg}\right.$ ) $\left.\mathrm{Mg}+\mathrm{Fe}^{2+}\right)$ with the IMA 12 differentiation and dotted line for the proposed differentiation specific to the asbestos problem. The uncertainty calculated on $\left(\mathrm{Mg} / \mathrm{Mg}+\mathrm{Fe}^{2+}\right)$ is negligible, on $\mathrm{S}_{\text {iapfu }}$ it is $0.3 \%$.

In the literature, hornblende fibres have been described in dust collected at aggregate grinding sites [30], in soils associated with actinolite [31] without being classified as asbestiform or in the lungs of taconite miners [32]. Magnesio-ferri-hornblende has been described in hydrothermal veins [33].

In the laboratory, grinding operations lead to the production of more or less elongated fragments (cleavage fragments). Some of these fragments have morphological and dimensional characteristics which are those of inhalable fibres as defined by the WHO. A proportion of particles characterised as asbestos fibres according to the WHO criteria include cleavage fragments, especially in the fraction of fibres whose $L / D$ ratio is less than 10 . Measurements made on WHO fibres (fourth AD-LAB set considered) reported on the diagram ( $\mathrm{Si}_{\text {apfu }}$ versus $\mathrm{Mg} / \mathrm{Mg}+\mathrm{Fe}^{2+}$ ) define a compositional field equivalent to that defined for fibres that are only asbestiform. This observation may seem surprising if one refers to the results acquired within the framework of the geological approach, the fine amphibole fibres are distributed throughout almost the entire diagram ( $\mathrm{Si}$ apfu versus $\mathrm{Mg} / \mathrm{Mg}+\mathrm{Fe}^{2+}$ ), whereas most of the very fine amphibole fibres cover a compositional field close to that of the asbestiform fibres. Although the analyses were not carried out on the same samples, we can wonder about the possibility that some of the very fine amphibole fibres are better produced by grinding cleavage fragments with a fibre morphology with "WHO" dimensions. This would be consistent with the observations made by Germine (1986) [34]. Studies of particles produced by manual grinding of more aluminous, acicular and prismatic calcic amphiboles should make it possible to verify this hypothesis. Another possible hypothesis is that the amphiboles which preferentially produce cleavage fragments with a fibre morphology having WHO dimensions during manual grinding have an origin (or part of their origin) close to that of the asbestiform fibres. This could explain why their chemical signature is close.

In the fifth set, the short fibres are added to the WHO fibres. Reported on the ( $\mathrm{Si}$ versus $\mathrm{Mg} / \mathrm{Mg}+\mathrm{Fe}^{2+}$ ) diagram, all these fibres define a compositional field equivalent to that defined for asbestiform and WHO-only fibres.

With 71 measurements, the fifth set allows for a consolidation of the definition for the "magnesioactinolitic-amphibole" domain, this number of measurements beginning to be significant in petrology (Bouchez [35]). Given the over-representation of the Armorican massif, the question of a possible sampling bias may arise. The proportion of measurements in the "magnesioactinolitic-amphibole" field of the total number of measurements made in the massifs of metropolitan France varies little from one massif to another while the number of analyses shows great variation (see Tab. 5 example).

In the five sets, a portion of the fibres with a magnesioferri-hornblende or magnesio-hornblende composition with a Si apfu greater than 7.32 and a portion of the actinolites with a Si apfu of less than 7.68 may change domain given the uncertainty of TEM-EDS elemental analyses.

With only a maximum of 13 measurements in the fifth set of AD-LAB measurements, the presence of two ferritschermakites and a ferro-actinolite outside its margins, 


\section{Amphibole fibres $D=1 \mu \mathrm{m} L / D$ ratio $>3$}

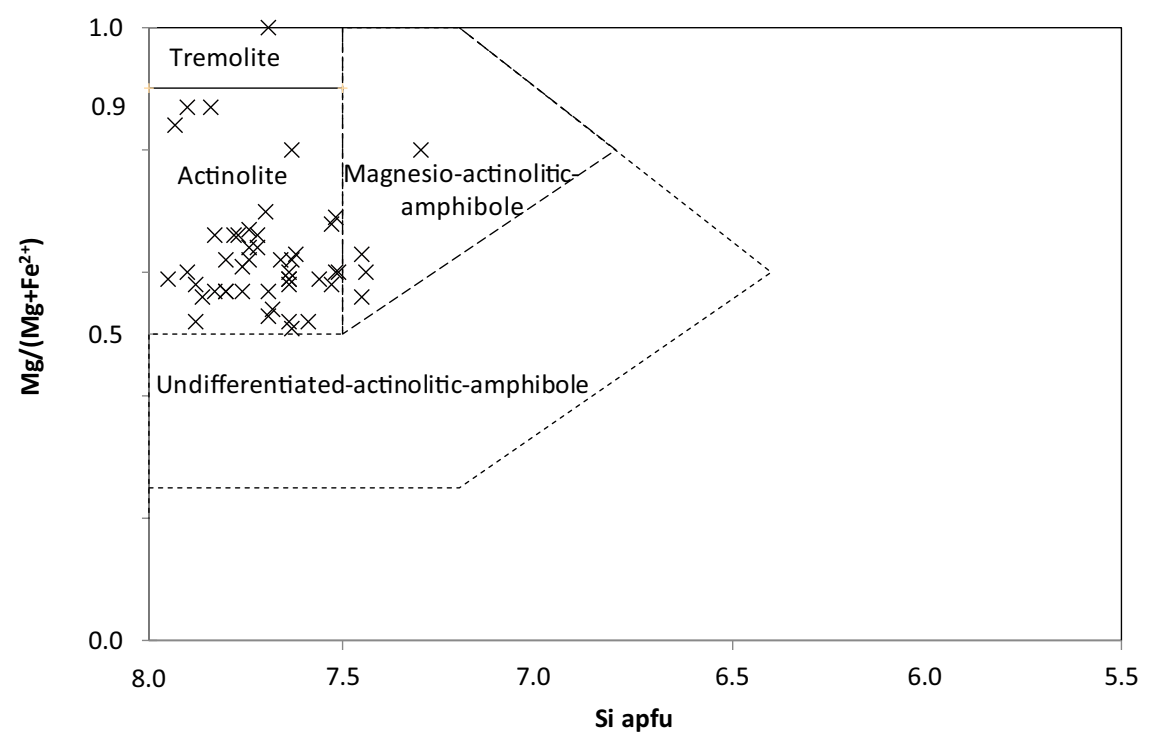

\section{Amphibole fibres $1<D<3 \mu \mathrm{m}$ and L/D ratio $>3$}

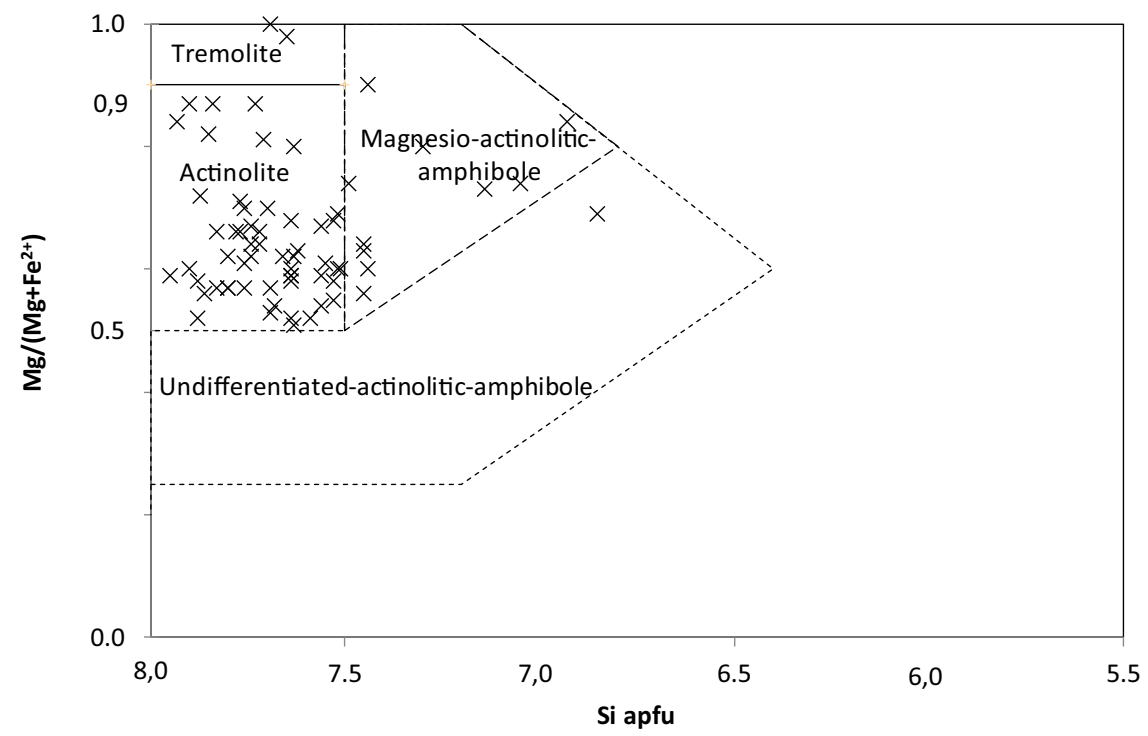

Fig. 11. Results for the AD-LAB analysed fibres that could be analysed with an EMP (diameter $>1 \mu \mathrm{m}$ ).

Table 5. Comparison between the MA (Armorican Massif), MC (Massif Central), Al (external massifs of the Alps), the number of analyses (No. of analyses) and the percentages (\% MAA) of fibres whose representative points for their chemical composition are located in the "Magnesio-Actinolitic-Amphibole" range with respect to the totality of analyses for each massif.

\begin{tabular}{lllll}
\hline Ratio & WHO AM/MC & WHO AM $/ \mathrm{Al}$ & $>0.5 \mu \mathrm{m} \mathrm{AM} / \mathrm{MC}$ & $>0.5 \mu \mathrm{m}$ AM/Al \\
\hline No. of analyses & 20 & 6.9 & 20 & 6.9 \\
\%MAA & 1.7 & 1.0 & 1.2 & 1 \\
\hline
\end{tabular}

This is for fibres with WHO dimensions and fibres longer than $0.5 \mu \mathrm{m}$. For example, for fibres with WHO dimensions, there are 20 times more analyses done in the Armorican Massif than in the Massif Central, the percentage of MAA fibres (magnesio-actinoliticamphibole) from the Armorican Massif is only 1.7 times greater than those of the Armorican Massif [sic]. Magnesio-actinoliticamphibole. 


\section{actinolite reference texts}

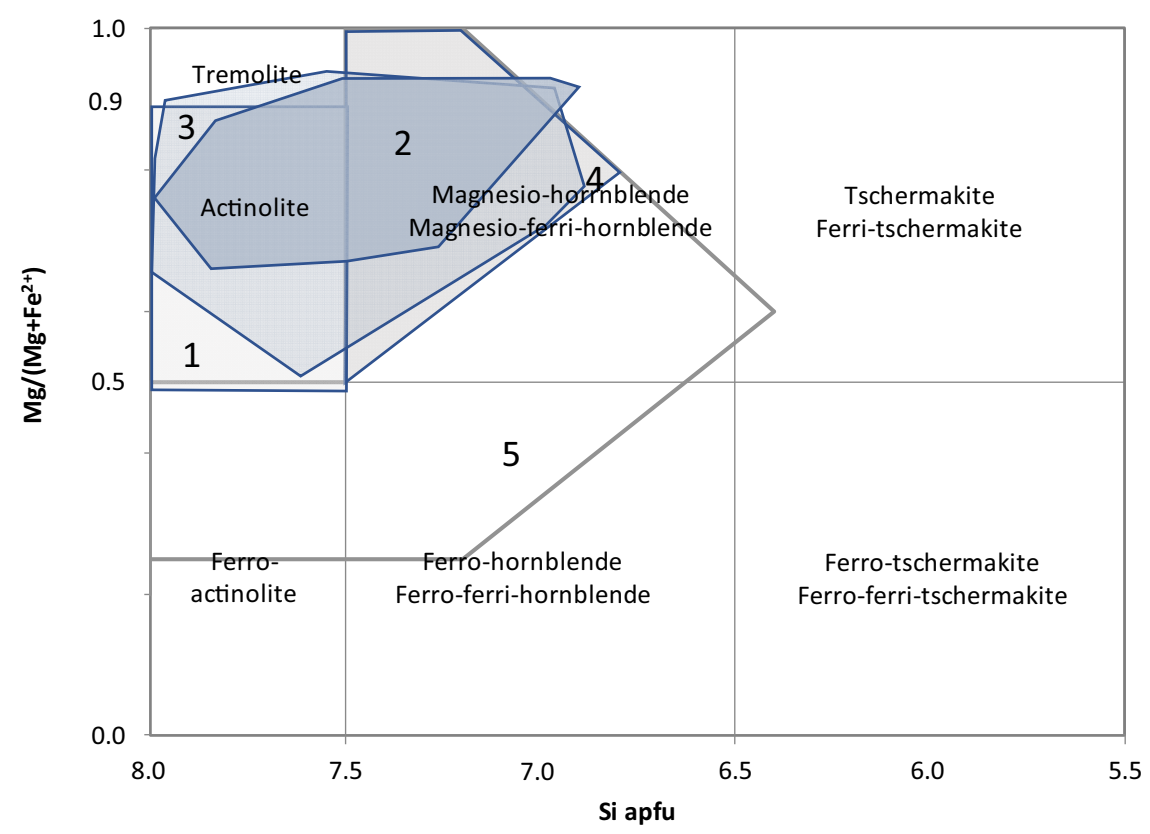

Fig. 12. Range covered by the chemical formula for actinolite proposed by: 1 EPA, 2 INSERM (Kirk-Othmer table), 3 VDI 3492 , 4 Magnesio-actinolitic-amphibole and 5 undifferentiated-actinolitic-amphibole.

\section{Fibrous calcium Amphiboles}

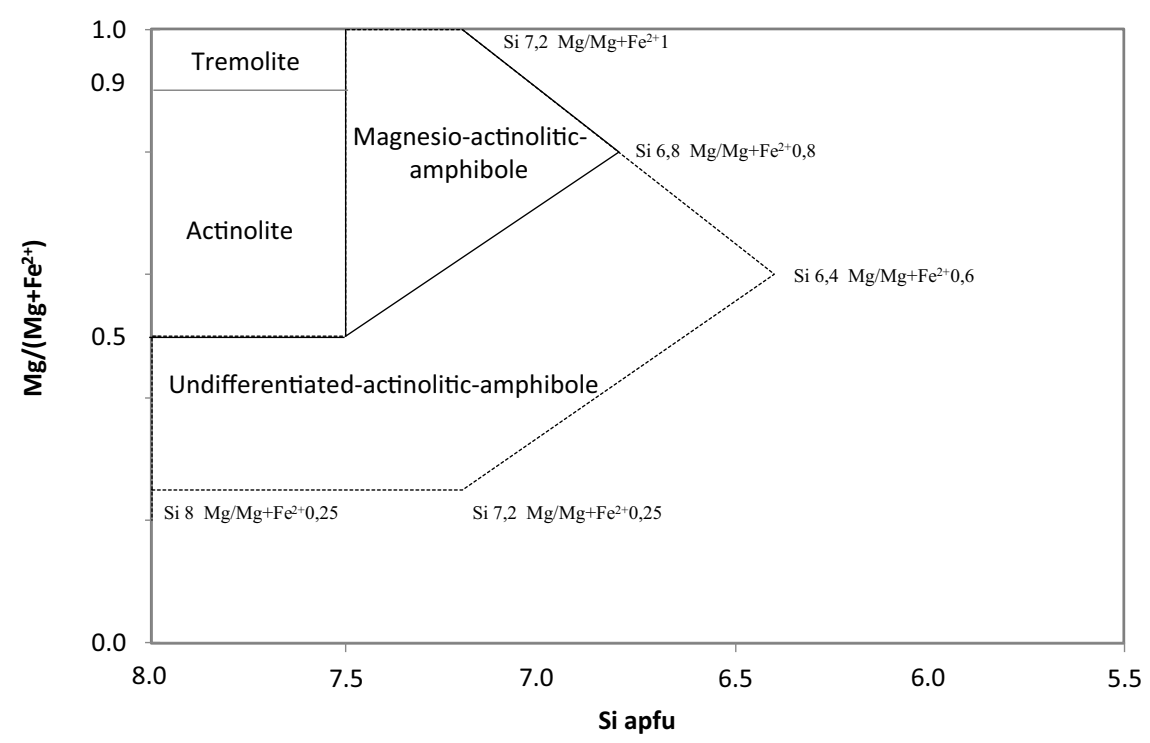

Fig. 13. Proposed compositional domains for asbestiform calcic amphiboles for LSAD use.

the geometry of the domain "undifferentiated-actinoliticamphibole" requires confirmation. The consolidation of the geometry of these domains involves the analysis of samples from massifs of other countries with a different geological history.

Only tremolites and actinolites were identified out of samples from New Caledonia. The geology of this massif is different from the massifs of metropolitan France.
Fibres were also observed in the processed samples that have a composition close to tremolite or actinolite: edenite, and more rarely amphiboles richer in sodium, calcium and potassium. These minerals are not in the domain of calcic amphiboles.

Some asbestiform varieties of amphiboles with a chemical composition close to tremolite (winchite, richterite [36] and fluoro-edenite [37]) have been shown to be 


\begin{tabular}{ll}
\hline Magnesio-hornblende & Magnesio-ferri-hornblende \\
\hline $\mathrm{Ca}_{2} \mathrm{Mg}_{2.5} \mathrm{Fe}_{2.5} \mathrm{Si}_{7.5} \mathrm{Al}_{0.5}(\mathrm{OH})_{2} \mathrm{O}_{22}$ & $\mathrm{Ca}_{2} \mathrm{Mg}_{2.25} \mathrm{Fe}^{2+}{ }_{2.25} \mathrm{Fe}^{3+}{ }_{0.5} \mathrm{Si}_{7.5} \mathrm{Al}_{0.5}(\mathrm{OH})_{2} \mathrm{O}_{22}$ \\
$\mathrm{Ca}_{2} \mathrm{Mg}_{5} \mathrm{Si}_{7.5} \mathrm{Al}_{0.5}(\mathrm{OH})_{2} \mathrm{O}_{22}$ & $\mathrm{Ca}_{2} \mathrm{Mg}_{4.4} \mathrm{Fe}^{3+}{ }^{3+.6} \mathrm{Si}_{7.5} \mathrm{Al}_{0.5}(\mathrm{OH})_{2} \mathrm{O}_{22}$ \\
$\mathrm{Ca}_{2} \mathrm{Mg}_{5} \mathrm{Si}_{7.2} \mathrm{Al}_{0.8}(\mathrm{OH})_{2} \mathrm{O}_{22}$ & $\mathrm{Ca}_{2} \mathrm{Mg}_{4.4} \mathrm{Fe}^{3+}{ }_{0.6} \mathrm{Si}_{7.2} \mathrm{Al}_{0.8}(\mathrm{OH})_{2} \mathrm{O}_{22}$ \\
$\mathrm{Ca}_{2} \mathrm{Mg}_{4} \mathrm{Fe} \mathrm{Si}_{6.8} \mathrm{Al}_{1,2}(\mathrm{OH})_{2} \mathrm{O}_{22}$ & $\mathrm{Ca}_{2} \mathrm{Mg}_{3.2} \mathrm{Fe}^{2+}{ }_{0.8} \mathrm{Fe}^{3+} \mathrm{Si}_{6.8} \mathrm{Al}_{1.2}(\mathrm{OH})_{2} \mathrm{O}_{22}$ \\
\hline
\end{tabular}

hazardous to human health and classified as carcinogenic by [38] and [39]. By analogy, the question on the degree of toxicity of "magnesio-actinolitic-amphibole" and "undifferentiated-actinolitic-amphibole" arises.

The BRGM's EMP-WDS data involved fibres with a diameter of $1 \mu \mathrm{m}$ to more than $10 \mu \mathrm{m}$. Spot chemical analyses of fibres less than $1 \mu \mathrm{m}$ in diameter, some of which are in the domains of magnesio-actinolitic-amphibole and undifferentiated-actinolitic-amphibole, have been excluded in this article. These measurements may be contaminated by nearby minerals because the sector analysed by the EMP-WDS is broader. AD-LAB's TEM-EDS data on fibres with a diameter between 1 and $3 \mu \mathrm{m}$ are comparable to BRGM's EMP-WDS data but in insignificant quantities (for ultrafine fibres). It is possible to measure much finer fibres with the TEM-EDS because the preparation makes it possible to observe isolated fibres.

\section{Conclusions}

In the standards and the reference texts, the determination of actinolite asbestos and tremolite asbestos in building materials is established from ranges of chemical compositions by element weight or by oxide weight. This approach was chosen because the performance of the EDS detectors was low, especially for light elements. In addition, as these varieties of minerals are present only very rarely in manufactured materials, the LSADs were unfamiliar with their analyses.

The search for asbestos has been extended to materials consisting of natural rocks (ballasts) or those that contain them (road asphalt, concrete). This approach is no longer sufficient. The characterisation of natural asbestos requires taking into account the structure of minerals as is the case in the diagram $\left(\mathrm{Si}_{\text {apfu }}\right.$ versus $\left.\mathrm{Mg} / \mathrm{Mg}+\mathrm{Fe}^{2+}\right)$. The EDS detectors that equip the latest electronic microscopes have a better resolution, which allows more precise chemical data to be acquired, the structural formula of the analysed fibres to be calculated and allows them to be characterized in terms of mineral species (e.g. the fluoro-edenite [37] and richterite and winchite from the Libby region [36]).

Whether through a conventional geological approach or through that of a laboratory specialised in the detection of asbestos, fibres classified as asbestiform observed in rocks from Metropolitan France and New Caledonia have a chemical composition that fully covers the fields of actinolite and tremolite. This corresponds to actinolite and asbestos tremolite, which is regulated in many countries.
The finest asbestiform fibres observed by the laboratory specialising in the detection of asbestos are also located in a compositional field that we call "magnesio-actinoliticamphibole." These fibres have not been described in the past as pathogenic. It is difficult to think that the toxicity of these fibres is inhibited by the mere fact of passing a delineation of chemical composition determined by convention by mineralogists. Given the use of chemical composition ranges by the LSADs, these fibres can currently be classified by mistake as actinolite or tremolite.

The ideal structural formulas for amphiboles that mark the boundary of the "magnesio-actinolitic-amphibole" compositional field are as follows:

see equation table in top of page.

The set of spot chemical analyses situates the fibres observed in this study in one of the two domains "magnesioactinolitic-amphibole" or "undifferentiated-actinolitic-amphibole." This is through the traditional geological approach or the LSADs approach.

\section{Implications and influences}

Accurate characterisation of calcic asbestos amphibole is necessary for physicians, hygienists, routine labs and geologists.

This work should help to allow these professions to put under the same name the same object. Indirectly this work may help to improve the definition of asbestos in standards. ISO 22262-1, 22262-2, 13794, 10312, NF X 43050, VDI 3492 standards.

\section{Funding sources}

This work was supported by the French "Credit Impot Recherche" of AD-LAB that is dedicated to scientific research.

The authors gratefully acknowledge the Directorate-General for Risk Prevention of the French Ministry of Ecological and Solidarity Transition for its partial help and financial support. We thank Dr. Abdérafi Charki for his careful reading of the final manuscript and his constructive comments.

\section{References}

1. R.A. Lemen, J.M. Dement, J.K. Wagoner, Epidemiology of asbestos-related diseases, Environ. Health Perspect. 34, 1 (1980) 
2. E.J. Chatfield, Review of: Sampling and analysis of consumer garden products that contain vermiculite EPA 744-r-00-010, August, 2000, in Vermiculite Conference 2001 Proceeding Paper, 2001 NIOSH, Revised Recommended Asbestos Standard, Cincinnati, OH: U.S. Department of Health, Education, and Welfare, Center for Disease Control

3. National Institute for Occupational Safety and Health, DHEW (NIOSH), Publication No. 77-169, 1976

4. IARC, Some Miscellaneous Pharmaceutical Substances (International Agency for Research on Cancer, Lyon, France, (1976)

5. IARC, WHO, Asbestos (Chrysotile, Amosite, Crocidolite, Tremolite, Actinolite and Anthophyllite). IARC Monographs on the Evaluation of Carcinogenic Risks to Humans (International Agency for Research on Cancer, Lyon, France, 2012), Vol. 100, pp. 164-179

6. B.W.S. Robinson, R.A. Lake, Advances in malignant mesothelioma, New Engl. J. Med. 353, 1591-1603 (2005)

7. I.L.G. Anabelle Gilg Soit, S. Ducamp, C. Gramond, et al., Résumé//Abstract, J. Natl. Cancer Inst. 105, 293-301 (2013)

8. L.A. Peipins, M. Lewin, S. Campolucci, et al., Radiographic abnormalities and exposure to asbestos-contaminated vermiculite in the community of Libby, Montana, USA, Environ. Health Perspect. 111, 1753 (2003)

9. B.S. Van Gosen, Reported Historic Asbestos Mines, Historic Asbetos Prospects, and Natural Occurrences of Asbestos in the Eastern United States, Open File Report 2005-1189, version 2.0

10. B.S. Van Gosen, Badley, Reported Historic Asbestos Mines, Historic Asbestos Prospects, and Natural Asbestos Occurrences in the Southwestern United States (Arizona, Nevada, and Utah), Open File Report 2008-1095

11. B.S. Van Gosen, Reported Historic Asbestos Prospects and Natural Asbestos Occurrences in the Central United States, 2006

12. G. Meeker, Asbestos sans mineralogy? A view from a different hilltop, Elements 5, 269 (2009)

13. F.C. Hawthorne, R. Oberti, G.E. Harlow, et al., Nomenclature of the amphibole supergroup, Am. Mineral. 97, 20312048 (2012)

14. B.E. Leake, A.R.P.S. Woolley, E.S. Charles, et al., Nomenclature of amphiboles: report of the Subcommittee on Amphiboles of the International Mineralogical Association Commission on new minerals and mineral names, Mineral. Mag. 61, 295-321 (1997)

15. W.J. Campbell, R.L. Blake, L.L. Brown, et al. Selected silicate minerals and their asbestiform varieties, Bur. Mines Info. 1977

16. ISO 13794 : Ambient air-Determination of asbestos fibresIndirect-transfer transmission electron microscopy method. International Organization for Standardization, 1999

17. National Research Council, Asbestiform Fibers: Nonoccupational Health Risks (National Academies Press, Washington, DC , 1984)

18. R.J. Lee, B.R. Strohmeier, K.L. Bunker, D.R. Van Orden, Naturally occurring asbestos: a recurring public policy challenge, J. Hazard. Mater. 153, 1-21 (2008)

19. VDI 3492, Indoor air measurement: ambient air measurement: measurement of inorganic fibrous particles: scanning electron microscopy method, June 2013
20. ISO, B.S. 14966, Ambient air determination of numerical concentration of inorganic fibrous particles-scanning electron microscopy method, 2002

21. M. Goldberg, D. Hémon, Health effects of major types of asbestos exposure, INSERM, Collective Expertise Collection, 1997

22. T. Schneider, L.S. Davies, S.T. Laurie, et al., Development of a method for the determination of low contents of asbestos fibres in bulk material, Analyst 123, 1393-1400 (1998)

23. C. Merlet, An accurate computer correction program for quantitative electron probe microanalysis, Microchim. Acta 114, 363-376 (1994)

24. A.J. Locock, An Excel spreadsheet to classify chemical analyses of amphiboles following the IMA 2012 recommendations, Comput. Geosci. 62, 1-11 (2014)

25. D. Lahondère, M. Misseri, X. Roy, Understanding asbestos via geology (General Review of Roads), p. 4.

26. A.M. Langer, A.D. Mackler, F.D. Pooley, Microscopical investigation of asbestos fibers, Environ. Health Perspect. 9, 63-80 (1974)

27. D.R. Van Orden, R.J. Lee, K.A. Allison, et al., Width distributions of asbestos and non-asbestos amphibole minerals. Indoor Built Environ. 18, 531-540 (2009)

28. Kirk-Othmer, Encyclopedia of Chemical Technology (John Wiley \& Sons, Inc., New York, 1978), Vol. 3, 3rd edition

29. H. Winchell, Nomenclature of amphiboles compiled by Bernard E. Leake, Am. Mineral. 63, 1023-1052 (1978)

30. S. Junttila, A. Tossavaitten, T. Hartikainen, et al., Airborne mineral dust at nine crushed rock plants in Finland, Appl. Occup. Environ. Hyg., 12, 882-886 (1997)

31. G.P. Meeker, H.A. Lowers, G.A. Swayze, et al., Mineralogy and Morphology of Amphiboles Observed in Soils and Rocks in El Dorado Hills, California, 2006

32. B. Gylseth, T. Norseth, V. et Skaug, Amphibole fibers in a taconite mine and in the lungs of the miners, Am. J. Indus. Med. 2, 175-184 (1981)

33. A.S. Baidya, J. Paul, D.C. Pal, et al., Mode of occurrences and geochemistry of amphibole in the Kolihan-Chandmari copper deposits, Rajasthan, India: insight into the oreforming process, Ore Geol. Rev. 80 1092-1110 (2017)

34. M. Germine, Asbestiform and Non-Asbestiform Amphiboles, Cadmium, and Zinc in Quarry Samples of Marble from Franklin and Sparta, Sussex County, New Jersey Geological Survey Geologic Report 15, New Jersey, 1986, 19 p.

35. J.L. Bouchez, Examples of automatic digital data processing in structural geology and petrology, University of Nantes Natural Science Institute, 1971

36. G.P. Meeker, A.M. Bern, I.K. Brownfield, et al., The composition and morphology of amphiboles from the Rainy Creek Complex, near Libby, Montana, Am. Mineral., 88, 1955-1969 (2003)

37. S. Mazziotti-Tagliani, G.B. Andreozzi, B.M. Bruni, et al., Quantitative chemistry and compositional variability of fluorine fibrous amphiboles from Biancavilla (Sicily, Italy). Periodico Mineral. 78, 65-74 (2009)

38. IARC, Fluoro-edenite, Monographs IARC, Vol. 111, Monograph 111-02, 2011

39. EPA/635/R-11/002F, Toxicological review of Libby amphibole asbestos, 2014 